\title{
INSPIRE-SAT 7, a Second CubeSat to Measure the Earth's Energy Budget and to Probe the Ionosphere
}

\author{
Mustapha Meftah ${ }^{1} * \mathbb{D}$, Fabrice Boust ${ }^{2}$, Philippe Keckhut ${ }^{1}$, Alain Sarkissian ${ }^{1}$ (D), Thomas Boutéraon ${ }^{1}$ (D), \\ Slimane Bekki ${ }^{1}$, Luc Damé ${ }^{1}$, Patrick Galopeau ${ }^{1}$, Alain Hauchecorne ${ }^{1}$ (D) Christophe Dufour ${ }^{1}$, \\ Adrien Finance 1,3 ${ }^{\mathbb{D}}$, André-Jean Vieau ${ }^{1}$, Emmanuel Bertran ${ }^{1}$, Pierre Gilbert ${ }^{1}$, Nicolas Caignard 1,4, \\ Clément Dias ${ }^{1}$, Jean-Luc Engler ${ }^{1}$, Patrick Lacroix ${ }^{1}$, Kévin Grossel ${ }^{2}$, Véronique Rannou ${ }^{2}$, Stéphane Saillant ${ }^{2}$, \\ Yannick Avelino ${ }^{5}$, Benjamin Azoulay ${ }^{6}$, Cyril Brand $^{6}{ }^{6}$, Carlos Dominguez ${ }^{6}$, Akos Haasz ${ }^{7}$, Agne Paskeviciute ${ }^{7}$, \\ Kevin Segura ${ }^{7}$, Pierre Maso ${ }^{4}$, Sébastien Ancelin ${ }^{4}$, Christophe Mercier ${ }^{8}$, Valentin Stee ${ }^{3}$, Antoine Mangin ${ }^{3}$, \\ David Bolsée ${ }^{9}$ and Catherine Billard ${ }^{10}$
}

1 LATMOS, CNRS, Université de Versailles Saint-Quentin-en-Yvelines, Université Paris-Saclay, Sorbonne Université (SU), 11 Boulevard d'Alembert, 78280 Guyancourt, France; Philippe.Keckhut@latmos.ipsl.fr (P.K.) Alain.Sarkissian@latmos.ipsl.fr (A.S.); Thomas.Bouteraon@latmos.ipsl.fr (T.B.);

Slimane.Bekki@latmos.ipsl.fr (S.B.); Luc.Dame@latmos.ipsl.fr (L.D.); Patrick.Galopeau@latmos.ipsl.fr (P.G.); Alain.Hauchecorne@latmos.ipsl.fr (A.H.); Christophe.Dufour@latmos.ipsl.fr (C.D.);

Adrien.Finance@latmos.ipsl.fr (A.F.); andre-jean.vieau@latmos.ipsl.fr (A.-J.V.); emmanuel.bertran@latmos.ipsl.fr (E.B.); pierre.gilbert@latmos.ipsl.fr (P.G.); nicolas.caignard@latmos.ipsl.fr (N.C.); clement.dias@latmos.ipsl.fr (C.D.); Jean-Luc.Engler@latmos.ipsl.fr (J.-L.E.); patrick.lacroix@latmos.ipsl.fr (P.L.)

2 DEMR, ONERA, Université Paris-Saclay, 6 Chemin de la Vauve aux Granges, 91123 Palaiseau, France; fabrice.boust@onera.fr (F.B.); Kevin.grossel@onera.fr (K.G.); Veronique.Rannou@onera.fr (V.R.); stephane.saillant@onera.fr (S.S.)

3 ACRI-ST-CERGA, 10 Avenue Nicolas Copernic, 06130 Grasse, France; Valentin.Stee@acri-st.fr (V.S.); Antoine.Mangin@acri-st.fr (A.M.)

check for
updates

Citation: Meftah, M.; Boust, F.; Keckhut, P.; Sarkissian, A.; Boutéraon T.; Bekki, S.; Damé, L.; Galopeau, P.; Hauchecorne, A.; Dufour, C.; et al. INSPIRE-SAT 7, a Second CubeSat to Measure the Earth's Energy Budget and to Probe the Ionosphere. Remote Sens. 2022, 14, 186. https://doi.org/ $10.3390 / \mathrm{rs} 14010186$

Academic Editor: Giancarlo Bellucci

Received: 13 November 2021 Accepted: 29 December 2021 Published: 1 January 2022

Publisher's Note: MDPI stays neutral with regard to jurisdictional claims in published maps and institutional affiliations.

Copyright: (C) 2022 by the authors. Licensee MDPI, Basel, Switzerland. This article is an open access article distributed under the terms and conditions of the Creative Commons Attribution (CC BY) license (https:// creativecommons.org/licenses/by/ $4.0 /)$.
4 PIT, OVSQ, 11 Boulevard d'Alembert, 78280 Guyancourt, France; pierre.maso@uvsq.fr (P.M.); sebastien.ancelin@uvsq.fr (S.A.)

5 Adrelys, 52 rue Paul Lescop, 92000 Nanterre, France; yavelino@adrelys.com

6 Oledcomm, 10-12 Av. de l'Europe, 78140 Vélizy-Villacoublay, France; benjamin.azoulay@oledcomm.net (B.A.) cyril.brand@oledcomm.net (C.B.); carlos.dominguez@oledcomm.net (C.D.)

7 ISIS-Innovative Solutions in Space B.V., Motorenweg 23, 2623CR Delft, The Netherlands; a.haasz@isispace.nl (A.H.); a.paskeviciute@isispace.nl (A.P.); k.segura@isispace.nl (K.S.)

8 AMSAT-Francophone, 14 bis rue des Gourlis, 92500 Rueil Malmaison, France; christophe.mercier@amsat-f.org

9 Belgian Institute for Space Aeronomy (BIRA-IASB), Ringlaan 3, 1180 Brussels, Belgium; David.Bolsee@aeronomie.be

10 Epidemiology and Modelling of Antibiotic Evasion (EMAE) Unit, Université de Versailles Saint-Quentin-en-Yvelines, Université Paris Saclay, Présidence et Services Centraux, 55 Avenue de Paris, 78035 Versailles, France; catherine.billard@uvsq.fr

* Correspondence: Mustapha.Meftah@latmos.ipsl.fr; Tel.: +33-180-285-179

Abstract: INSPIRE-SAT 7 is a French 2-Unit CubeSat $(11.5 \times 11.5 \times 22.7 \mathrm{~cm})$ primarily designed for Earth and Sun observation. INSPIRE-SAT 7 is one of the missions of the International Satellite Program in Research and Education (INSPIRE). Twice the size of a $4 \times 4$ Rubik's Cube and weighing about $3 \mathrm{~kg}$, INSPIRE-SAT 7 will be deployed in Low Earth Orbit (LEO) in 2023 to join its sister satellite, UVSQ-SAT. INSPIRE-SAT 7 represents one of the in-orbit demonstrators needed to test how two Earth observation CubeSats in orbit can be utilized to set up a satellite constellation. This new scientific and technological pathfinder CubeSat mission (INSPIRE-SAT 7) uses a multitude of miniaturized sensors on all sides of the CubeSat to measure the Earth's energy budget components at the top-of-theatmosphere for climate change studies. INSPIRE-SAT 7 contains also a High-Frequency (HF) payload that will receive HF signals from a ground-based HF transmitter to probe the ionosphere for space weather studies. Finally, this CubeSat is equipped with several technological demonstrators (total solar irradiance sensors, UV sensors to measure solar spectral irradiance, a new Light Fidelity (Li-Fi) wireless communication system, a new versatile telecommunication system suitable for CubeSat). After introducing the objectives of the INSPIRE-SAT 7 mission, we present the satellite definition and the mission concept of operations. We also briefly show the observations made by the UVSQ-SAT 
CubeSat, and assess how two CubeSats in orbit could improve the information content of their Earth's energy budget measurements. We conclude by reporting on the potential of future missions enabled by CubeSat constellations.

Keywords: climate observation and monitoring; Earth's energy budget; ionosphere; nanosatellite; CubeSat constellations

\section{Introduction}

INSPIRE-SAT 7 is a scientific and technological pathfinder CubeSat mainly developed to measure the Earth's Energy (or Radiation) Budget (ERB) at the top-of-the-atmosphere (TOA) and to probe the ionosphere. INSPIRE-SAT 7 is a 2 U CubeSat $(11.5 \times 11.5 \times 22.7 \mathrm{~cm})$ with a total mass budget limit of $3.0 \mathrm{~kg}$ and a power limit consumption of $3 \mathrm{~W}$ (orbit averaged power). INSPIRE-SAT 7 is a continuation of the UltraViolet and infrared Sensors at high Quantum efficiency onboard a small SATellite (UVSQ-SAT) programme [1]. UVSQ-SAT was successfully launched on 24 January 2021 by the Falcon 9 rocket, and represents the first French CubeSat measuring key scientific parameters (Outgoing Shortwave Radiation (OSR), Outgoing Longwave Radiation (OLR), Earth's magnetic field). The UVSQ-SAT CubeSat has been performing continuously ERB measurements since February 2021 [2]. In 2023, INSPIRE-SAT 7 will join its precursor satellite UVSQ-SAT in orbit to provide a global coverage of Earth observation with a shorter time span, and then replace UVSQ-SAT. The orbit selection is directly related to the scientific goals. It is necessary to take into account the constraints of the rules governing the space debris mitigation (international treaties, French space operation act), and the launch opportunities. The selected orbit is a Sun-synchronous orbit with a maximum altitude of $600 \mathrm{~km}$ and a local time at descending node (LTDN) of $\sim 09: 30 \mathrm{~h}$ (vs. $\sim 21: 30 \mathrm{~h}$ for UVSQ-SAT), which will result in an atmospheric reentry of the satellite within 25 years. INSPIRE-SAT 7 is planned to have a 2-years nominal mission lifetime, including the commissioning phase.

The first objective of INSPIRE-SAT 7 is to improve the UVSQ-SAT technologies that are used to measure the ERB components and derive the Earth's Energy Imbalance (EEI), which is the difference between global mean solar radiation absorbed by the Earth system and thermal infrared radiation emitted to space by it. EEI results primarily from the increase in greenhouse gases levels and drives the global change. It is a crucial quantity for testing climate models and for the prediction of the future course of global warming. INSPIRE-SAT 7 will measure the incoming solar radiation (total solar irradiance (TSI)) and the outgoing terrestrial radiation (OSR and OLR) using 12 miniaturized Earth's radiative sensors (thermopiles with carbon nanotubes and optical solar reflectors).

The second objective is to validate new technologies that help to characterize the state of the ionosphere for space weather studies and test an innovative approach based on the combined use of a ground-based High-Frequency (HF) transmitter and of a HF receiver onboard the INSPIRE-SAT 7 CubeSat. The attenuation of HF waves by the ionosphere crossing will be measured during the entire CubeSat trajectory, when it is visible from the ground transmitter. This kind of technology is important for monitoring the state of the ionosphere and, in particular, for wave propagation predictions. Indeed, multiple phenomena originating from the Sun or the lower of atmosphere can strongly disturb the ionosphere and wave propagation, even posing a threat to orbiting satellites in the case of powerful solar storms.

The third objective of the INSPIRE-SAT 7 mission is to validate new technologies for other purposes. For instance, 14 photodiodes will be used to measure the TSI but also solar radiation in the ultraviolet range, whose variability directly impacts the ozone layer and the temperatures in the middle atmosphere. INSPIRE-SAT 7 will also operate the first Li-Fi (or Light Fidelity) module in orbit onboard a CubeSat. The aim is to demonstrate that light-based wireless communication is a credible alternative to traditional copper 
harnesses for small satellites. Finally, an amateur radio payload will be tested onboard INSPIRE-SAT 7. It is a complete 'open-source' bidirectional telemetry printed circuit board for CubeSat. This device will be associated with the audio transponder (system that receive a signal at a given frequency and transmit it), which has already be validated onboard the UVSQ-SAT CubeSat.

The last objective of the INSPIRE-SAT 7 mission is educational. It is to provide handson experience and training to students with a NewSpace approach (science objectives, mission analysis, design, construction, CubeSat integration and test, mission operations, management, cost and risks, mission and product assurance). This training of the new generation in the field of the NewSpace is important for a variety of future space missions for Earth constellation and for Astronomy and Astrophysics.

The goal of the manuscript is to present an overview of the INSPIRE-SAT 7 mission. Section 2 outlines the scientific objectives of INSPIRE-SAT 7. Section 3 provides a description of the INSPIRE-SAT 7 CubeSat and its operational requirements. Section 4 presents a preliminary analysis of the expected results from combined measurements by INSPIRESAT 7 and UVSQ-SAT using a numerical model simulating ERB measurements by two CubeSats in orbit. This analysis will also demonstrate the interest in implementing a satellite constellation to improve the determination of the EEI.

\section{Scientific Objectives of the INSPIRE-SAT 7 Mission}

\subsection{Earth's Energy Budget Components and Earth's Energy Imbalance}

With the emergence of the NewSpace, an international project of a nanosatellite/ microsatellite constellation for the study of the Earth's global environment and climate has become possible. Climate observation is played out more than ever in space, and global warming is acknowledged as the major environmental issue of the 21st century. Constellations of small satellites, possibly hosting different payloads, could be the best solution to characterize the spatio-temporal variability of the ERB components. Most ERB satellites have tended to only measure the total sum of radiation changes, not the individual components. The radiometric calibration uncertainties also limit the capability of the current generation of satellite-based instruments highlighting the need to have International calibration standards facilities. The current challenge is to measure at high spatio-temporal the individual ERB components that influence the atmospheric radiative transfer and heat budget. This topic represents the primary scientific objective of the INSPIRE-SAT 7 mission.

Earth's energy budget describes the various types and amounts of energy that enter and leave the Earth system. ERB is composed of the incoming solar shortwave radiation, OSR (outgoing shortwave radiation reflected by the atmosphere including surface, clouds, and aerosols), and OLR (outgoing long-wave radiation emitted by the surface and atmospheric components such as greenhouse gases and clouds). The different components of ERB clearly depends on many atmospheric factors that are changing, notably greenhouse gases levels, surface albedo (linked to vegetation and land use), aerosols, and clouds. The global energy budget is also affected by external changes (incoming solar radiation) and internal climate variability. When the incoming and total outgoing energy fluxes $(=\mathrm{OSR}+\mathrm{OLR})$ are in balance, Earth is in radiative equilibrium and the climate system is relatively stable. Today, the Earth's incoming energy flux is greater than the outgoing energy flux mostly due to the increase in greenhouse gases levels which has led an enhanced greenhouse effect and hence reduction in the OLR. As a result, the planet is gaining energy and the surface is heating up which tends to increase OLR and so reestablish the Earth radiative balance [3]. One of the objectives of the INSPIRE-SAT 7 mission is to measure the ERB components and EEI. EEI represents a measure of the excess of energy that is being stored in the climate system as the result of the to anthropogenic forcing (increase in greenhouse gases levels). EEI has been identified as a crucial quantity [4] for testing climate models and for predicting the future course of global warming. Therefore, accurate EEI 
measurements would certainly help to improve our understanding of climate change and the projections of future climate by climate models.

Combining multiple ERB measurements in an optimal way using a small satellite constellation holds considerable promise for better estimation of EEI, and thus assessing the status of global climate change, improving climate models, and testing the effectiveness of mitigation actions.

A recent study [5] demonstrates the benefits of having independent satellite TOA radiation observations and ocean heat content measurements for tracking 'long-term' changes in EEI. The vast majority of EEI ends up warming the ocean. The remainder heats the land, melts ice, and warms the atmosphere. The authors of this recent study [5] show that independent satellite and in situ observations yield statistically indistinguishable decadal

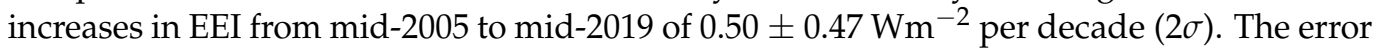
bar is of the order of the EEI. This estimation needs to be improved. The recommended objective is to detect any global 'long-term' trend with high accuracy (stability better than $\pm 0.2 \mathrm{Wm}^{-2}$ per decade). From mid-2005 to mid-2019, the EEI trend appears to be primarily due to an increase in absorbed solar radiation associated with decreased reflection by clouds and sea-ice and a decrease in outgoing longwave radiation (OLR) due to increases in the levels of greenhouse gases and water vapor. These changes combined exceed a positive trend in OLR due to increasing global mean temperatures.

To date, the best estimate of the Earth's energy imbalance is obtained from the change in the heat accumulated in the ocean. However, the absorption of heat by the ocean acts as a buffer, slowing the rate of surface warming. The ocean heat content measurements performed by the Argo automated floats are excellent but the accuracy of the global mean estimation is hampered by the limited spatial sampling of the Argo network. In addition, the absorption of heat by the ocean acts as a buffer, slowing the rate of surface warming. Ocean heat content data do not contain much information on 'short-term' dynamics.

To solve the 'short term' dynamics, one needs fine spatio-dynamics of the EEI. An important consideration is the temporal resolution of EEI estimates, as stated previously. A single satellite, typically on a Sun-synchronous orbit like the ERB satellite, can only provide measurements at two specific local solar times along the satellite trace and therefore resolve poorly diurnal variations. Diurnally-resolved ERB measurements are crucial for improving the representation of the fast physical processes in climate models, notably key cloud parameterizations. A constellation of small satellites, for instance in a trailing formation (multiple satellites orbiting on the same path separated by a specific time to view at different local times) with instruments that combine measurements with a narrow field of view and a wide field of view would represent an interesting strategy and a major step in our capabilities in monitoring EEI on a diurnal scale. The 'long-term' behavior of EEI is associated with the convolution of rapid processes and dynamic phenomena at longer temporal and spatial scales of the atmosphere/ocean system.

Thus, in that case, the best strategy for monitoring EEI on long time scales is to follow the 'long term' temporal evolution of the thermal content of the oceans since the greatest part of the excessive heat (89\% over the period 1970-2018) is absorbed by the ocean [3].

Nowadays, 'short-term' measurements of ERB components at high spatio-temporal resolution have to be a priority. These measurements using a small satellite constellation (called Terra-F thereafter) are crucial for advancing our understanding of climate change because the radiative balance is partly driven by the radiative impacts of aerosols and clouds, which are highly variable spatially and temporally (with a strong diurnal scale) and are still relatively poorly quantified. These measurements would also allow constraining better poorly known radiative forcing associated with surface albedo and UV solar irradiance. A small satellite constellation can provide a global, 24/7 coverage that could improve the spatio-temporal sampling of ERB 'short-term' measurements (day and year) owing to incoming solar radiation, which has the largest effect on the radiation balance, followed in importance by the cloud cover. The relevant scientific objective is to obtain ERB 'short-term' measurements with fine spatial resolution (a few tens of $\mathrm{km}$ ) and a temporal resolutions of 
three hours (comparable to the temporal scale of meteorological forecast) with an accuracy of a few $\mathrm{Wm}^{-2}$.

The UVSQ-SAT CubeSat [1] launched in 2021, represents our first pathfinder for a constellation to measure the ERB components and EEI. The objective is to establish that miniaturized broadband radiometers absolutely calibrated through an extensive calibration program can be built and operated in space for measuring the ERB components with an excellent accuracy. INSPIRE-SAT 7 is our second CubeSat dedicated to the measurements of the ERB components. It represents the first steps towards a small satellite constellation (Terra-F) dedicated to the study of climate. Table 1 presents part of the scientific objectives to be achieved by UVSQ-SAT, INSPIRE-SAT 7, and the future Terra-F constellation.

These measurements must be combined with observations at the TOA using instruments on board satellites to provide 'short-term' information. Measurements with good spatio-temporal resolutions are crucial for advancing our understanding of climate change as explained above. Currently, we do not know whether the cloud-related changes will amplify, mitigate, or have little impact on the Earth's global temperature rise due to anthropogenic radiative forcings. Furthermore, we ignore the impact of radiative forcing associated with anthropogenic aerosols that modify the properties of clouds. Global climate models have limitations with respect to these two issues. This highlights the importance of space missions to achieve accurate measurements with excellent spatio-temporal resolutions.

The observations are important for validating climate models and the magnitude of EEI at the TOA. The incident solar flux represents an input to the model. The solar radiation reflected by the Earth and the outgoing long wavelength radiation are calculated at the model level and must be compared with those measured.

Table 1. Scientific requirements (UVSQ-SAT, INSPIRE-SAT 7, and future Terra-F constellation).

\begin{tabular}{|c|c|c|c|c|}
\hline Requirements & UVSQ-SAT & & & \\
\hline Parameter & Absolute accuracy & Stability per year & Spatial resolution & Temporal resolution \\
\hline OSR & $\pm 10.00 \mathrm{Wm}^{-2}$ & $\pm 5.00 \mathrm{Wm}^{-2}$ & $2500 \mathrm{~km}$ & 30 days \\
\hline OLR & $\pm 10.00 \mathrm{Wm}^{-2}$ & $\pm 1.00 \mathrm{Wm}^{-2}$ & $2500 \mathrm{~km}$ & 30 days \\
\hline Requirements & INSPIRE-SAT 7 & & & \\
\hline Parameter & Absolute accuracy & Stability per year & Spatial resolution & Temporal resolution \\
\hline OSR & $\pm 5.00 \mathrm{Wm}^{-2}$ & $\pm 1.00 \mathrm{Wm}^{-2}$ & $2500 \mathrm{~km}$ & 10 days with 2 CubeSats \\
\hline OLR & $\pm 5.00 \mathrm{Wm}^{-2}$ & $\pm 1.00 \mathrm{Wm}^{-2}$ & $2500 \mathrm{~km}$ & 10 days with 2 CubeSats \\
\hline Requirements & Terra-F & & & \\
\hline Parameter & Absolute accuracy & Stability per decade & Spatial resolution & Temporal resolution \\
\hline TSI & $\pm 0.54 \mathrm{Wm}^{-2}$ & $\pm 0.14 \mathrm{Wm}^{-2}$ & - & $24 \mathrm{~h}$ \\
\hline OSR & $\pm 1.00 \mathrm{Wm}^{-2}$ & $\pm 0.10 \mathrm{Wm}^{-2}$ & $10-100 \mathrm{~km}$ & Diurnal cycle (3 h) \\
\hline OLR & $\pm 1.00 \mathrm{Wm}^{-2}$ & $\pm 0.10 \mathrm{Wm}^{-2}$ & $10-100 \mathrm{~km}$ & Diurnal cycle (3 h) \\
\hline EEI & $\pm 1.00 \mathrm{Wm}^{-2}$ & $\pm 0.10 \mathrm{Wm}^{-2}$ & - & - \\
\hline
\end{tabular}

\subsection{Ionosphere}

Another scientific objective of the INSPIRE-SAT 7 mission is based on ionospheric variability due to various solar and space weather effects and exploring different techniques of monitoring and modeling the ionosphere. Conditions of space weather could be unpredictable. Monitor the solar activity (UV observations) and probe the ionosphere status in near real time is fundamental to protect the satellites, but also navigations system and power grid system from breakdown. CubeSat can perform part of all space weather monitoring jobs. The number and configuration of the small satellite constellation is key into bringing the relevant space weather data to scientists. These observations can be carried out in the same CubeSat constellations dedicated to the measurements of ERB components and solar irradiance. 
The Earth's atmosphere is made up of several layers, including the ionosphere which contains, as its name suggests, a lot of ions, but also electrons. When a large solar flare occurs, the amount of UV rays and X-rays entering the atmosphere increases. This radiation will tear electrons from molecules in the atmosphere, forming new ions in the ionosphere and making it denser. Once the solar eruption has passed, natural chemical recombination processes return the ionosphere to its normal state.

Then, the characterization of the ionosphere is of renewed interest in the space weather problematic. Indeed, the ionospheric disturbances have a great influence on the quality of many telecommunications and observation services. It has practical importance because, among other functions, it influences radio propagation to distant places on the Earth. The real-time knowledge of the ionosphere and its behavior become a major asset.

The ionosphere is part of Earth's upper atmosphere. It extends from $\sim 50 \mathrm{~km}$ altitude up to about $1000 \mathrm{~km}$ above sea level. The ionosphere as a whole is electrically neutral.When the solar radiation strikes the atmosphere chemical constituents, electrically charged atoms and molecules are produced. The ionosphere is a dynamic and highly variable environment depending on solar activity and on the effects of geomagnetic storms. An excellent knowledge of the structure of the ionosphere represents an important scientific issue. The behavior of the ionosphere has to be monitored. It is necessary to understand the spatial and temporal evolution of the plasma and to investigate all scales of wave activity ranging from planetary waves and tides down to small-scale traveling ionospheric disturbances generated at the ground.

Currently, most of the information about the ionosphere behavior comes from groundbased ionospheric sounders [6,7], and indirectly from Geostationary Operational Environmental Satellites (GOES) but also from Swarm [8], FormoSat-3/COSMIC (Constellation Observing System for Meteorology, Ionosphere and Climate), e-POP/CASSIOPE (Enhanced Polar Outflow Probe) [9], the Norwegian NorSat-1 [10]. With the exception of certain sounders able to operate with oblique incidence [11], these devices give information only on the local vertical. The INSPIRE-SAT 7 mission proposes an innovative approach based on one ground-based HF transmitter and one HF receiver onboard a CubeSat. The analysis of the HF signal received after passing through the ionosphere will provide information of the propagation medium along the portion of the CubeSat trajectory visible from the ground transmitter, i.e., approximately a $1000 \mathrm{~km}$ arc.

As part of the INSPIRE-SAT 7 mission, we will test a new technology to perform ionospheric measurements and new concepts to analyze our data like map reconstruction technics.

\subsection{Total Solar Irradiance and Solar Spectral Irradiance (SSI) in the Herzberg Continuum}

The influence of the Sun on climate and the role of solar variability in climate change remains a topic of considerable scientific and societal importance. TSI [12] provides nearly all the energy driving the Earth's climate system and represents a key scientific parameter. The solar spectrum [13] and its variability also represent key inputs not only for solar physics but also for climate physics. Since the variation of UV solar irradiance during a Solar Cycle is much larger, in proportion, than variations in total solar irradiance, it plays an important role in regional climate change through interactions with stratospheric ozone. UV solar irradiance and its variability thus represents a key input for both climate and solar physics. New technologies to carry out solar measurements will be tested in orbit.

\section{Description of the INSPIRE-SAT 7 Mission and Mission Operations}

INSPIRE-SAT 7 is a scientific and technical LATMOS/ONERA mission based on the implementation of a second CubeSat to study the Sun and the Earth. We hope that INSPIRESAT 7 will double transmission capacity of UVSQ-SAT [1], and the constellation will be able to relay the data from two observation satellites simultaneously. Above all, INSPIRE-SAT 7 will ensure UVSQ-SAT ERB data continuity.

The INSPIRE-SAT 7 mission is based on a space segment, which comprises a 2-Unit CubeSat (Figure 1) and the uplink and downlink satellite links. The INSPIRE-SAT 7 mission 
also has a ground segment with at least one LATMOS UHF/VHF station located at $\mathrm{Ob}$ servatoire de Versailles Saint-Quentin-en-Yvelines (OVSQ, France) that will provide radio interfaces with the CubeSat. The ground segment is also based on a mission operations center, from which INSPIRE-SAT 7 will be managed and a ground networks that will connect the other ground elements to one another. Finally, the LATMOS science operation centre will be responsible for the calibration of the instruments onboard the CubeSat, and for helping the scientific community to process and analyse the data obtained by the instruments being flown.

The INSPIRE-SAT 7 mission commits to respect the French space operation act. This act translates the international commitments that France has made under United Nations treaties and the requirements than space operators (LATMOS) must fulfill with regard to the safety of people, property and the environment, and to public health. One of the obligations is to deplete all CubeSat onboard sources of stored energy and disconnect all energy generation sources when they are no longer required for mission operations or post-mission disposal or control to a level which can not cause an explosion or deflagration large enough to release orbital debris or break up the CubeSat. One of the commitments is to passivate the batteries or to demonstrate that most debris from the battery rupture should be contained within the CubeSat. Several failure modes (internal short circuit, internal thermal rise due to high load discharge rate, overcharging and excessive charge rate, excessive discharge rate, excess temperatures due to orbital environment and high discharge combined, polarity reversal due to over-discharge caused by continuous load during periods of negative power generation vs. consumption) might result in INSPIRESAT 7 batteries explosion. In this case, most debris from the INSPIRE-SAT 7 batteries (Panasonic NCR18650B) rupture will be contained within the CubeSat due to the lack of penetration energy. However, this scenario is not considered. Indeed, if the INSPIRE-SAT 7 batteries fail, they are expected to vent gas rather than explode. A test with the INSPIRESAT 7 batteries (qualification model) in its enclosure will be done $\left(16 \mathrm{~V}, 0.2 \mathrm{~A}, 80{ }^{\circ} \mathrm{C}\right)$ to validate the ventilation mechanisms in case of overpressure.

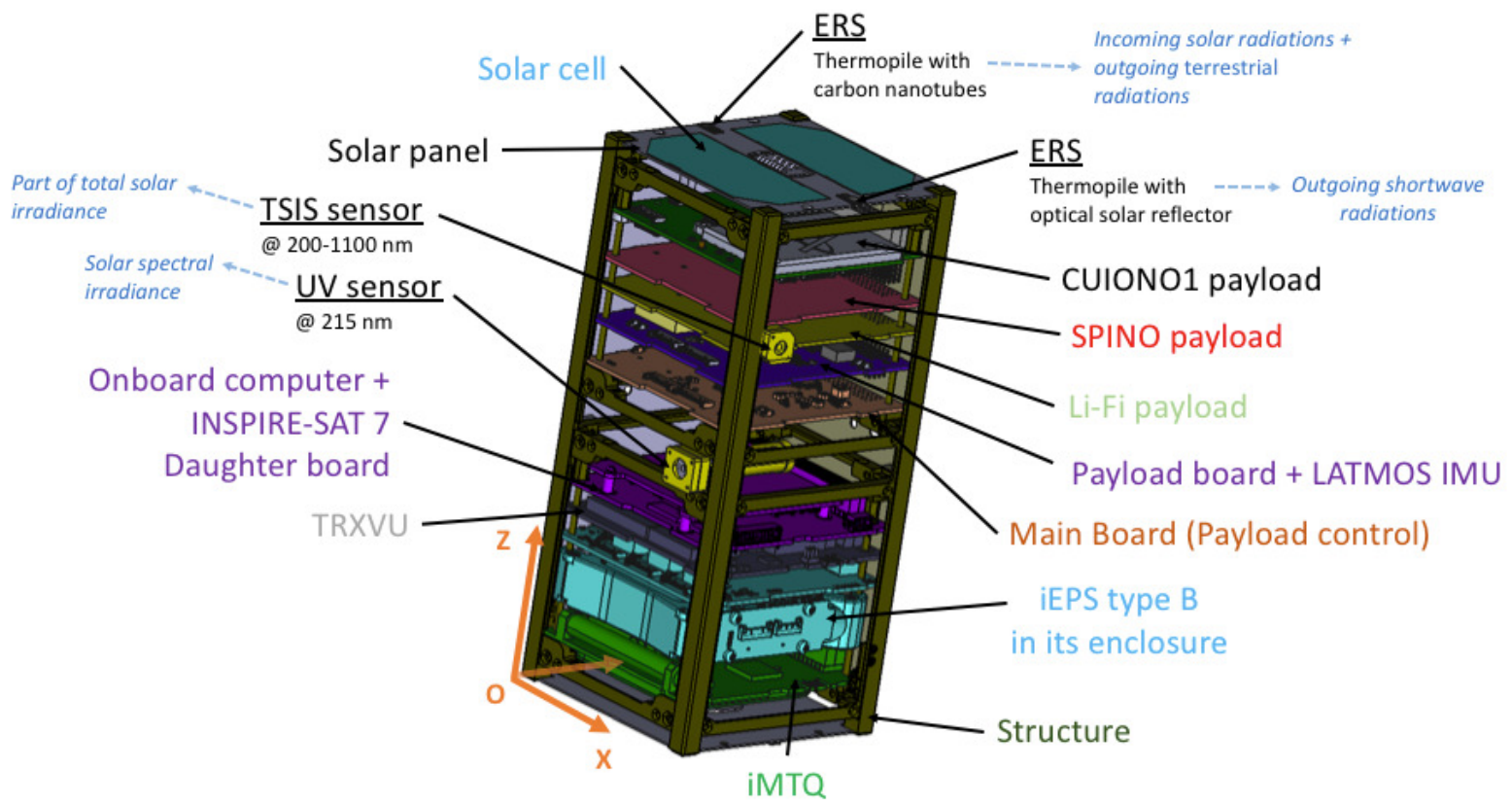

Figure 1. Computer-aided design of the INSPIRE-SAT 7 CubeSat with all printed circuit boards (PCBs) and payload instruments (ERS, TSIS sensors, UV sensors (standard and new generation), Li-Fi payload, CUIONO1 payload, SPINO payload, IMU). 


\subsection{The Space Segment-The INSPIRE-SAT 7 CubeSat Platform}

INSPIRE-SAT 7 is a nanosatellite project based on CubeSat standard [14,15]. INSPIRESAT 7 is a two-unit (2U) CubeSat designed to provide $11.5 \mathrm{~cm} \times 11.5 \mathrm{~cm} \times 22.7 \mathrm{~cm}$ useful volume, which represents the allowable physical envelope of the stowed satellite. LATMOS is prime contractor of the 2U CubeSat with the support of ONERA, French industrial partners, radio amateurs, and a manufacturer (ISIS) to build a dedicated satellite platform. Main characteristics of the INSPIRE-SAT 7 CubeSat are given in Table 2. The INSPIRE-SAT 7 platform (Figure 1) is mainly based on the same subsystems and functions as those used in UVSQ-SAT [1]. The INSPIRE-SAT 7 CubeSat is made of several subsystems such as the mechanical structure, the power supply subsystem, the attitude determination and control subsystem (ADCS), the telemetry/tracking and command and data handling subsystem (CDHS), and the communication subsystem. INSPIRE-SAT 7 also has many payloads (Earth Radiative Sensors (ERS), Total Solar Irradiance Sensors (TSIS), Ultra-Violet Sensors (UVS), IONOspheric payload (CUIONO1) with its antenna, Li-Fi payload, amateur radio SPINO payload, amateur radio audio transponder, 3-axis accelerometer/gyroscope/compass LATMOS inertial measurement unit (IMU)) to meet the requirements of the mission.

The INSPIRE-SAT 7 power supply subsystem is different from that used in UVSQ-SAT [1]. It is based on an Electric Power Supply (iEPS) that includes a 4-cell battery pack with $45 \mathrm{Whr}$ capacity. INSPIRE-SAT 7 consists of 6 solar panels with 20 Azurspace solar cells at high efficiency ( $30 \%$ for beginning of life). The solar cells could generate between $3.5 \mathrm{~W}$ to $3.8 \mathrm{~W}$ (orbit average power (OAP) in LEO). The following assumptions are taken into account when calculating the CubeSat generated power:

- The satellite is spinning at $2^{\circ} \mathrm{s}^{-1}$ rate around each axis,

- The efficiency of the solar cells is set to $29.11 \%$ that takes into account mechanical and assembly losses, and aging of the solar cells (1 year),

- Solar cells temperature is taken to be $20^{\circ} \mathrm{C}$,

- The solar flux is assumed to be $1362 \mathrm{Wm}^{-2}$ [12].

The INSPIRE-SAT 7 ADCS subsystem is identical from that used in UVSQ-SAT [1]. It is mainly based on a magnetorquer board (iMTQ) and 6 coarse photodiodes to estimate the Sun's direction. INSPIRE-SAT 7 does not have an active pointing system like UVSQSAT. To solve this issue, we developed new methods (Tri-Axial Attitude Determination (TRIAD), Multiplicative Extended Kalman Filter (MEKF)) to have a knowledge of the satellite attitude. These methods were validated with UVSQ-SAT data in orbit [16], and represent an important issue for the INSPIRE-SAT 7 scientific analysis.

The INSPIRE-SAT 7 CDHS subsystem is close to that used in UVSQ-SAT [1]. It is based on an onboard computer (OBC) with a LATMOS motherboard (iOBC) and a daughterboard (DB) used for interfacing with the platform sensors ( 6 temperature sensors and 6 coarse photodiodes). It is also used for interfacing with the payload electronic board. OBC communicates with the LATMOS payload electronic board (8 general purpose input/output (GPIO) pins, serial peripheral interface (SPI) data line), which manages the payload sensors. It is mainly based on an enhanced flash micro-controller (PIC18F4685), a voltage reference, a variable gain setting, a polarization voltage, an analog multiplexer, and an analog-to-digital converter (ADC).

The communication subsystem is based on a VHF/UHF transceiver (TRXVU) and a deployable antenna system (two antennas with $60 \mathrm{~cm}$ in length for VHF, two antennas with $20 \mathrm{~cm}$ in length for UHF). The satellite will communicate in the amateur band (UHF selection of $437.410 \mathrm{MHz}$ and VHF of $145.970 \mathrm{MHz}$ ), which requires a validation from International Amateur Radio Union (IARU). 
Table 2. INSPIRE-SAT 7 CubeSat properties.

\begin{tabular}{|c|c|c|}
\hline Properties & Value & Comments \\
\hline Orbit & Sun-synchronous orbit & Maximum altitude of $600 \mathrm{~km}, \mathrm{LTDN}$ of 09:30 \\
\hline Design life time & 2 years for LEO & 3 years desired \\
\hline Launch date & Q1 2023 & Launch vehicle: Falcon 9 \\
\hline Size & $2 \mathrm{U}$ & $11.5 \mathrm{~cm}(\mathrm{X}) \times 11.5 \mathrm{~cm}(\mathrm{Y}) \times 22.7 \mathrm{~cm}(\mathrm{Z})$ \\
\hline Mass & $3.0 \mathrm{~kg}$ & Maximum with margins \\
\hline Solar cells & 20 & 3G30A solar cells provided by Azurspace \\
\hline Batteries & 45Wh@16V & 4 Panasonic batteries (NCR18650B) with heaters \\
\hline Power generated & $3.8 \mathrm{~W}$ & OAP in LEO \\
\hline Power consumption & $3.2 \mathrm{~W}$ & Maximum orbit average with margins \\
\hline \multirow[t]{3}{*}{ ADCS } & 3-axis magnetometer & Measurements of the local Earth magnetic field \\
\hline & 3 -axis magnetorquer & $0.2 \mathrm{Am}^{2}$ magnetic dipole \\
\hline & 6 SLCD-61N8 photodiodes & Coarse estimation of the Sun's direction $(\theta)$ \\
\hline \multirow[t]{5}{*}{ CDHS and OBC } & $400 \mathrm{MHz}, 32$-bit ARM9 & Processor \\
\hline & $32 \mathrm{MB}$ SDRAM & Synchronous Dynamic Random Access Memory \\
\hline & $2 \times 2$ GB SD-cards & Non-volatile data storage (SD card redundancy) \\
\hline & $1 \mathrm{MB}$ NOR flash & Code storage \\
\hline & $\mathrm{I}^{2} \mathrm{C}, \mathrm{SPI}, \mathrm{UARTs}$ & UART is only used for debugging $\mathrm{iOBC}$ \\
\hline Data downlink & $1.2 / 9.6 \mathrm{kbps}$ & UHF BPSK (437.410 MHz) communication \\
\hline Data uplink & $9.6 \mathrm{kbps}$ & VHF FSK (145.970 MHz) communication \\
\hline Ground contact station & Less than $1 \mathrm{~h}$ per day & LATMOS station \\
\hline Redundancy stations & LATMOS & Other stations: amateur radio partners \\
\hline Downlink UVSQ-SAT data & 1.8 Mbyte per day & Maximum during a day \\
\hline Uplink UVSQ-SAT data & 0.3 Mbyte per day & Maximum during a day \\
\hline \multirow[t]{8}{*}{ Payload } & 12 ERS & ERB measurements \\
\hline & 4 TSIS & TSI measurements \\
\hline & 10 UVS & UV SSI and ozone measurements \\
\hline & 1 CUIONO1 payload & Ionospheric measurements \\
\hline & 1 Li-Fi payload & Wireless communication system \\
\hline & 1 SPINO payload & Functions for amateur radio community \\
\hline & Audio transponder & FM live retransmission (amateur radio) \\
\hline & $1 \mathrm{IMU}$ & 3-axis accelerometer/gyroscope/compass \\
\hline Launch adapter & ISIPOD or Quad-pack & CubeSat deployer with a satellite mass up to $3 \mathrm{~kg}$ \\
\hline
\end{tabular}

\subsection{The Space Segment-The INSPIRE-SAT 7 CubeSat Payload}

\subsubsection{The ERS Sensors}

To measure with accuracy the incoming solar radiation (TSI) and the Earth outgoing radiation (OSR and OLR), the INSPIRE-SAT 7 mission will use 12 ERS sensors (see their location in Figure 2).

INSPIRE-SAT 7 ERS sensors are similar to those used onboard UVSQ-SAT. INSPIRESAT 7 has twelve broadband radiometers $\left(180^{\circ}\right.$ field of view angle) that measure the Earth's radiation balance. The principle of this technology is explained in the UVSQ-SAT description manuscript [1]. To improve the results obtained with UVSQ-SAT, it is necessary to increase the sampling frequency (acquisitions every $10 \mathrm{~s}$ or better). Table 3 provides the technical expected performance of the ERS and temperature sensors to measure with high accuracy the incoming solar radiation and the Earth outgoing radiation. 


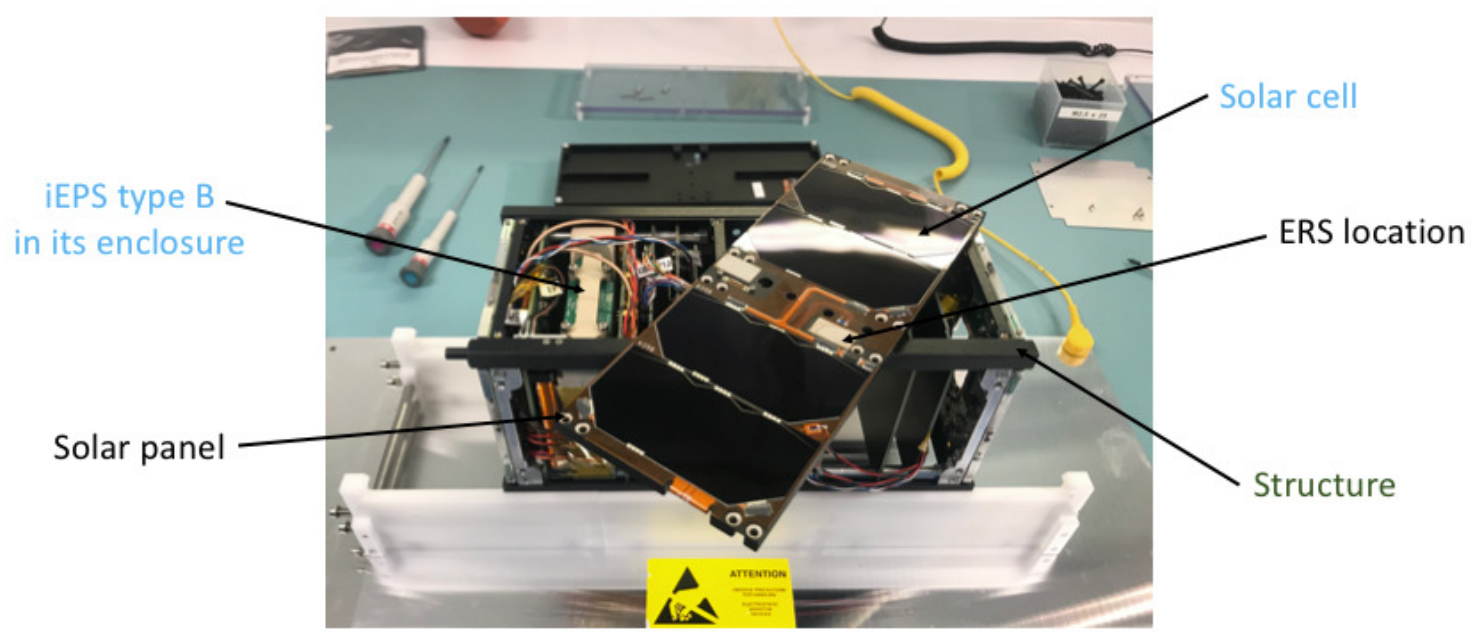

Figure 2. INSPIRE-SAT 7 during integration phase in November 2021. View of ERS location.

Table 3. ERS and temperature sensors technical requirements. $\mathrm{N}$ is the number of parts.

\begin{tabular}{lllllll}
\hline Type & Location & N & Sensitivity & Range & Resolution & Noise \\
\hline ERS $_{\mathrm{cn} 1}$ & $+\mathrm{X},-\mathrm{X},+\mathrm{Y},-\mathrm{Y}$ & 4 & $1.5 \mu \mathrm{V} / \mathrm{Wm}^{-2}$ & {$[-4500 \ldots 4500 \mu \mathrm{V}]$} & $34.3 \mathrm{nV} / \mathrm{bit}$ & $150 \mathrm{nV} \mathrm{rms}$ \\
$\mathrm{ERS}_{\mathrm{sr} 1}$ & $+\mathrm{X},-\mathrm{X},+\mathrm{Y},-\mathrm{Y}$ & 4 & $1.5 \mu \mathrm{WV} / \mathrm{Wm}^{-2}$ & {$[-4500 \ldots 4500 \mu \mathrm{V}]$} & $34.3 \mathrm{nV} / \mathrm{bit}$ & $150 \mathrm{nV} \mathrm{rms}$ \\
$\mathrm{ERS}_{\mathrm{cn} 2}$ & $+\mathrm{Z},-\mathrm{Z}$ & 2 & $0.2 \mu \mathrm{V} / \mathrm{Wm}^{-2}$ & {$[-750 \ldots 750 \mu \mathrm{V}]$} & $5.7 \mathrm{nV} / \mathrm{bit}$ & $25 \mathrm{nV} \mathrm{rms}$ \\
$\mathrm{ERS}_{\mathrm{sr} 2}$ & $+\mathrm{Z},-\mathrm{Z}$ & 2 & $0.2 \mu \mathrm{W} / \mathrm{Wm}^{-2}$ & {$[-750 \ldots 750 \mu \mathrm{V}]$} & $5.7 \mathrm{nV} / \mathrm{bit}$ & $25 \mathrm{nV} \mathrm{rms}$ \\
$\mathrm{T}_{\mathrm{ERS}}$ & 2 per side & 12 & $1.0 \mu \mathrm{A} \mathrm{K}{ }^{-1}$ & {$[-70 \ldots 70 \mu \mathrm{A}]$} & $0.5 \mathrm{nA} / \mathrm{bit}$ & $100 \mathrm{nA} \mathrm{rms}$ \\
\hline
\end{tabular}

Another area of improvement is linked to the sensitivity of the ERS sensors. As part of the INSPIRE-SAT 7 mission, the ERS sensors on the lateral faces have been enlarged compared to those used on UVSQ-SAT. Four ERS sensors are based on nanothermopiles (active area of $10 \mathrm{~mm} \times 10 \mathrm{~mm}$, responsivity of $\sim 1.5 \mu \mathrm{V}$ per $\mathrm{Wm}^{-2}$ ) with carbon nanotubes $\left(\mathrm{ERS}_{\mathrm{cn} 1}\right)$. Four ERS sensors are based on nano-thermopiles (active area of $10 \mathrm{~mm} \times 10 \mathrm{~mm}$, responsivity of $\sim 1.5 \mu \mathrm{V}$ per $\mathrm{Wm}^{-2}$ ) with optical solar reflector $\left(\mathrm{ERS}_{\mathrm{sr} 1}\right)$. Two ERS sensors are based on nano-thermopiles (active area of $5 \mathrm{~mm} \times 5 \mathrm{~mm}$, responsivity of $\sim 0.2 \mu \mathrm{V}$ per $\mathrm{Wm}^{-2}$ ) with carbon nanotubes $\left(\mathrm{ERS}_{\mathrm{cn} 2}\right)$. Two ERS sensors are based on nano-thermopiles (active area of $5 \mathrm{~mm} \times 5 \mathrm{~mm}$, responsivity of $\sim 0.2 \mu \mathrm{V}$ per $\mathrm{Wm}^{-2}$ ) with optical solar reflector $\left(\mathrm{ERS}_{\mathrm{sr} 2}\right)$. Finally, twelve temperature sensors (2-terminal integrated circuit temperature transducer) are used to measure the interface temperature of these ERS sensors. Indeed, it is necessary to monitor the temperature ( $T_{E R S}$ ) of the ERS sensors with a high accuracy to consider the temperature radiation loss of the nano-thermopiles (Stefan-Boltzmann law).

The INSPIRE-SAT 7 mission uses the six SLCD-61N8 photodiodes (sensitivity spectral range between 400 and $1100 \mathrm{~nm}$ ) to measure incoming solar radiation (TSI) and outgoing solar radiation (OSR).

\subsubsection{The TSIS and UVS Sensors (Standard and New Generation)}

To measure with accuracy TSI and SSI, it is fundamental to develop instruments that are calibrated to the International standards. These instruments must be accurate in-orbit, and require in-orbit calibration with internal (lamps) and/or external sources (stars). Solar space-based instruments exposed to the space environment usually degrade $[17,18]$ due to the harsh environment in which the instruments are expected to operate. Indeed, the space environment is considered hazardous to spacecraft. It results in materials degradation. An understanding of the degradation phenomena of space-based instruments is fundamental to achieve the expected scientific objectives resulting from these instruments. CubeSat missions offer possibilities for testing new technologies. In INSPIRE-SAT 7, several sensors 
will be used to observe the Sun and the Earth, and to validate in-orbit technologies. The INSPIRE-SAT 7 mission will use four TSIS sensors (200-1100 nm, transmission of $0.1 \%$ ) based on S1226-44BQ silicon photodiode (TO-5 package). The principle of this technology is shown in Figure 3. The INSPIRE-SAT 7 mission will also use four UVS $_{N G}$ sensors of new generation $(215-220 \mathrm{~nm}$, bandwidth of $20-30 \mathrm{~nm})$ for the direct measurement of the Herzberg continuum, three $\mathrm{UVS}_{2}$ sensors $(308 \mathrm{~nm}$, bandwidth of $10 \mathrm{~nm}$, transmission of $15 \%$ ), and three $\mathrm{UVS}_{3}$ sensors ( $340 \mathrm{~nm}$, bandwidth of $5 \mathrm{~nm}$, transmission of $25 \%$ ). Table 4 provides the technical expected performance of the TSIS and UVS sensors to observe the Sun and the Earth's atmosphere.
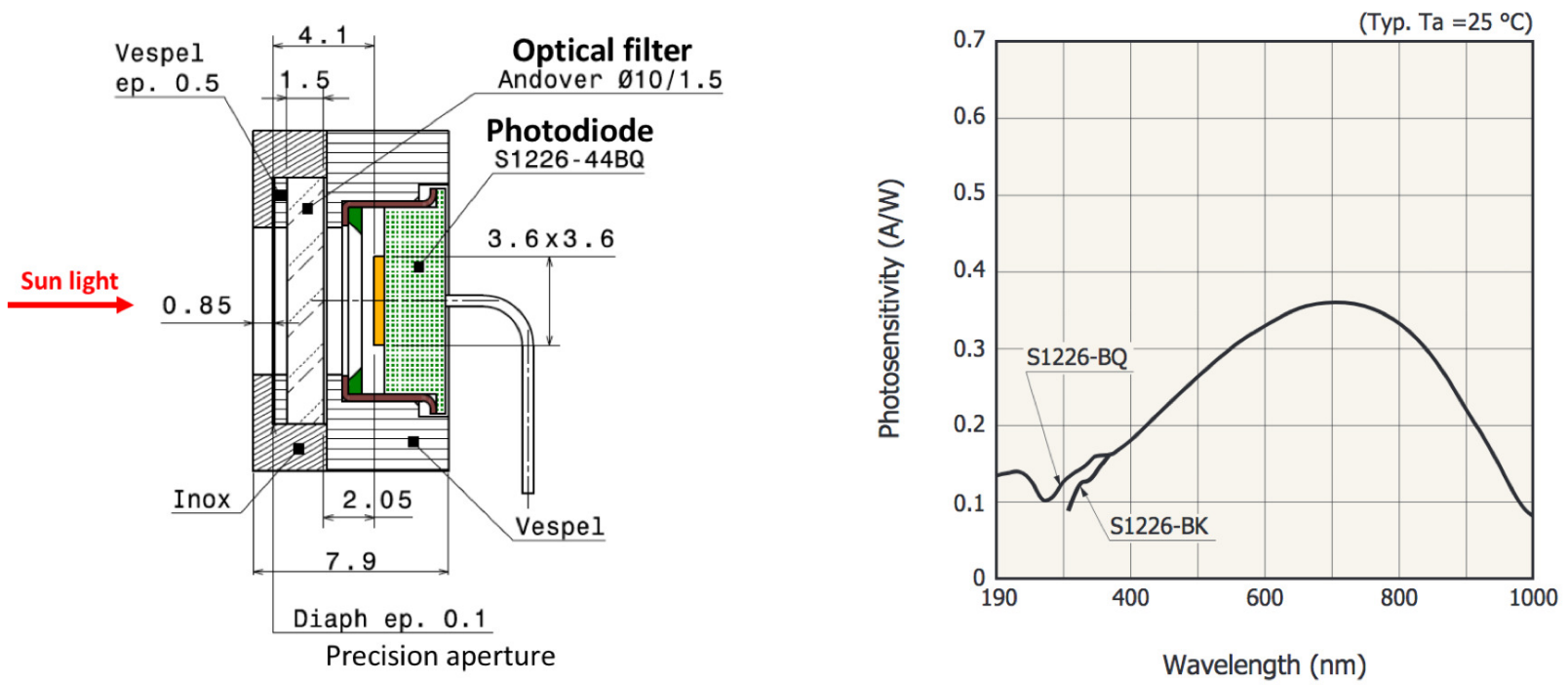

Figure 3. Design of the TSIS and standard UVS sensors $\left(\mathrm{UVS}_{2}\right.$ and $\left.\mathrm{UVS}_{3}\right)$.

Table 4. UVS and TSIS sensors technical requirements with their photoresponsivity $(\mathrm{P})$.

\begin{tabular}{llllllll}
\hline Sensor & $\mathbf{N}$ & Aperture & $\lambda$ & $\mathbf{P}$ & Range & Resolution & Noise \\
\hline TSIS & 4 & $\varnothing 1 \mathrm{~mm}$ & $0-1100 \mathrm{~nm}$ & $\sim 0.21 \mathrm{AW}^{-1}$ & {$[0 \ldots 250 \mathrm{nA}]$} & $9.5 \times 10^{-4} \mathrm{nA} / \mathrm{bit}$ & $<0.1 \mathrm{nA} \mathrm{rms}$ \\
$\mathrm{UVS}_{N G}$ & 4 & $500 \times 800 \mu \mathrm{m}$ & $215 \mathrm{~nm}$ & $\sim 0.01 \mathrm{AW}^{-1}$ & {$[0 \ldots 250 \mathrm{nA}]$} & $9.5 \times 10^{-4} \mathrm{nA} / \mathrm{bit}$ & $<0.1 \mathrm{nA} \mathrm{rms}$ \\
$\mathrm{UVS}_{2}$ & 3 & $\varnothing 3 \mathrm{~mm}$ & $308 \mathrm{~nm}$ & $\sim 0.14 \mathrm{AW}^{-1}$ & {$[0 \ldots 3000 \mathrm{nA}]$} & $11.4 \mathrm{pA} / \mathrm{bit}$ & $<0.1 \mathrm{nA} \mathrm{rms}$ \\
$\mathrm{UVS}_{3}$ & 3 & $\varnothing 3 \mathrm{~mm}$ & $340 \mathrm{~nm}$ & $\sim 0.15 \mathrm{AW}^{-1}$ & {$[0 \ldots 3000 \mathrm{nA}]$} & $11.4 \mathrm{pA} / \mathrm{bit}$ & $<0.1 \mathrm{nA} \mathrm{rms}$ \\
\hline
\end{tabular}

\subsubsection{The CUIONO1 Payload}

The INSPIRE-SAT 7 mission develops an innovative approach based on one groundbased HF transmitter and one HF receiver onboard a CubeSat to probe the ionosphere. The signal will be transmitted from an HF antenna located in France and received by the INSPIRE-SAT 7 CubeSat (Figure 4). For this first mission, there will be no synchronization between the transmitter and the receiver. Hence, only the addition of three or four pure continuous sinusoidal signals will be transmitted and the amplitude attenuation due to the path through the ionosphere will be measured. Taking into account the evolution of cutoff frequencies with the incidence angle, the transmitted frequency will be set between $8 \mathrm{MHz}$ and $20 \mathrm{MHz}$. The CUIONO1 payload consists of one antenna $(98 \times 98 \times 7 \mathrm{~mm}$, $100 \mathrm{~g}, 40 \mathrm{~mW}$ and $2000 \mathrm{~mW}$ during deployment) and one Software Defined Radio (SDR) electronic board $(89.3 \times 93.3 \times 13.6 \mathrm{~mm}, 137 \mathrm{~g}, 1400 \mathrm{~mW}$ OAP $)$, which will receive, digitize and process the HF signal. The antenna is below the $+Z$ face of the CubeSat solar panel (not shown in Figure 1). 


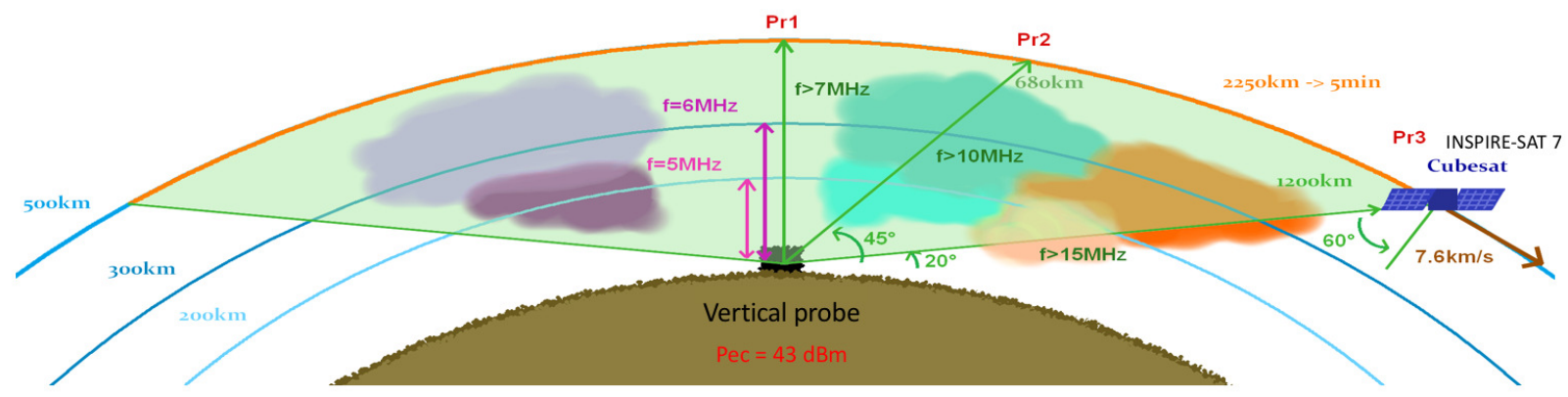

Figure 4. Principle of the measurement along the CubeSat orbit. During the time where the satellite is direct line of sight, the incidence varies and hence the cutoff frequency.

\section{- $\quad$ The HF antenna}

For HF frequency, a matched broadband antenna should be several meters long. However, we preferred to use an unmatched but flight proven VHF antenna. This antenna has an efficiency of -40 to $-20 \mathrm{~dB}$ according the received frequency between $8 \mathrm{MHz}$ and $20 \mathrm{MHz}$. The integration time will be adjusted to compensate the attenuation due to the antenna. As the wave polarization will rotate during the ionosphere crossing, two cross dipole antenna are required. These antennas should be preferably orientated in a plane perpendicular to the line joining the transmitter and the satellite. Small antennas have smooth patterns and do not require an accurate knowledge of the satellite orientation.

\section{- $\quad$ The SDR electronic board}

The CUIONO1 payload is based on the TOTEM SDR electronic unit developed by the Spanish company Alén Space. The analogic front-end and the ADC has been modified to receive the HF signals. Due to the selection of an unmatched antenna, the noise factor is determined by the low noise factor of the first amplifier (LNA) and not by the background noise that is often the case for HF frequencies. The integration time $\left(T_{i}\right)$ must maximized to improve the signal to noise ratio (SNR). However, to avoid a Doppler frequency migration greater than the Doppler bin, $T_{i}$ must meet the relation: $T_{i}<\sqrt{\lambda / \gamma}$ where $\lambda$ is the wavelength and $\gamma$ the radial acceleration. $\gamma$ is maximum when the satellite passes to zenith.

For a $500 \mathrm{~km}$ altitude satellite $\gamma<160 \mathrm{~m} \cdot \mathrm{s}^{-2}$, which limit $T_{i}$ to $306 \mathrm{~ms}$ for a $20 \mathrm{MHz}$ signal. We selected $T_{i}=300 \mathrm{~ms}$, which led to a very comfortable SNR (assuming $43 \mathrm{dBm}$ power emission and reasonable parameters for the link budget calculation). Nevertheless, the main issue in receiving the sounder signal could arise from parasite signals.

To minimize the amount of transferred data, only the spectrum around the transmitted frequencies will be computed. Taking into account the Doppler shift and the SDR clock stability, we estimated that the total frequency shift will be less than $850 \mathrm{~Hz}$ (on each side). Consequently, we selected $\mathrm{f}_{\mathrm{bw}}=2 \mathrm{kHz}$ frequency bandwidth resolution. Assuming 3 frequencies will be sent simultaneously, with two polarizations, a $300 \mathrm{~ms}$ integration time, a sampling period $T a=1.8 \mathrm{~s}$ and a $5 \mathrm{~min}$ total recording time, the data amount to be transferred to the OBC will be close to $600 \mathrm{~kb}$. $T a=1.8 \mathrm{~s}$ leads to a spatial sampling of one measurement around each $15 \mathrm{~km}$. A better resolution is possible ( $T a$ and $T_{i}$ can be decreased) for a cost of an increase of the transferred data amount or a decrease of the sounding area.

\section{- $\quad$ Communication with INSPIRE-SAT 7 OBC}

The CUIONO1 payload with its SDR electronic board communicates directly with the satellite's on-board computer. To comply with the satellite power budget, the SDR electronic board will only be activated when passing over the sounder that is located in France. Before each pass, the $\mathrm{OBC}$ will sent to the SDR electronic board the acquisitions parameters (absolute time, $\mathrm{Ti}, \mathrm{Ta}, \mathrm{f}_{\mathrm{bw}}$, the transmitted frequency list, number of acquisitions...). A the 
end of the pass, measured data will be written in an electrically-erasable programmable read-only memory (EEPROM) that the OBC will read in differed time.

\section{- Calibration}

To measure the impact of ionosphere on the attenuation, the transmitting and receiving antennas must be calibrated. Firstly the transmitting one has been calibrated with the help of a small drone carrying a reference antenna. In a second stage, the cubesat antenna is attached to the drone and flies over the same transmitting antenna. An inertial unit gives the positions and the attitude of the antenna under the drone during the measurements. The SDR electronic board transfer function is calibrated with reference signals in Laboratory.

For next CubeSat missions, an evolution of CUIONO1 payload is planned with the introduction of a GPS electronic board that will allow us to synchronize transmitting and receiving devices in order to measure also the ionosphere crossing time delay. We will also consider the possibilities to use other transmitters to gain information on ionosphere behaviors over other places around the world. Of course, receiver constellations could be considered.

\subsubsection{The Li-Fi Payload}

The Li-Fi payload aims to demonstrate the performance of Li-Fi technology in real space conditions through a point-to-point communication of $5 \mathrm{Mbps}$. The Li-Fi payload integrates the last generation of Li-Fi chipset. Oledcomm and LATMOS wish to prove the use of this Li-Fi chipset during a successful space-based mission in operational environment. The Li-Fi payload consists on a power stage, a micro-controller able to manage the I2C protocol and to drive the ASIC. The optical stage will consist of a light-emitting diode (LED) and a photodiode, allowing a unidirectional communication. The main goal is to demonstrate that $\mathrm{Li}-\mathrm{Fi}$ communication is not only feasible in space, but also that it is possible to achieve similar performance to traditional connections using copper harnesses. Main characteristics of the INSPIRE-SAT $7 \mathrm{Li}$-Fi are given in Table 5.

Table 5. Li-Fi payload characteristics.

\begin{tabular}{ll}
\hline Parameters & Li-Fi Payload Performances \\
\hline Parameters & Li-Fi payload characteristics \\
Protocol of communication & I2C \\
Data Rate & $5 \mathrm{Mbps}$ \\
Distance of communication & 1 to $2 \mathrm{~cm}$ \\
Field of view & $10^{\circ}$ \\
Wavelength & $940 \mathrm{~nm}$ \\
PCB dimensions & $90 \times 95 \times 8 \mathrm{~mm}$ \\
Weight & $70 \mathrm{~g}$ \\
Consumption & $1 \mathrm{~W}$ peak \\
Power Supply & $5 \mathrm{~V}$ \\
Telemetry & Data rate, latency, jitter \\
Telemetry & $<200$ Bytes per communication with the OBC \\
\hline
\end{tabular}

The $5 \mathrm{Mbps}$ data rate is imposed by the Li-Fi modem. Indeed, the ASIC used allows to reach speeds of the order of Gbps. Within the framework of the mission and in order to validate the performances stated in Table 5, periodic measurements will be carried out. During these data exchanges, the speed, latency and jitter are measured and transmitted to the INSPIRE-SAT 7 OBC.

3.2.5. The SPINO Amateur Radio Payload and the LATMOS Audio Transponder (LAT 2)

SPINO $(90 \times 95 \times 8 \mathrm{~mm}, 80 \mathrm{~g}, 200 \mathrm{~mW}$ OAP $)$ is a versatile telecommunication solution suitable for CubeSat. Operating in UHF and VHF bands, it features tight integration with amateur radio service and the worldwide amateur radio community. The development of the SPINO payload was initiated by enthusiasts involved in non-profit/educational space 
projects. Since 2019, the project is supported by the joint efforts of two non-profit organizations: AMSAT-Francophone (http:/ / site.amsat-f.org (accessed on 12 November 2021)) and the hackerspace Electrolab (http:/ / electrolab.fr (accessed on 12 November 2021)).

The SPINO board features functions dedicated to the spacecraft infrastructure:

- Receiver function for remote control commands from ground,

- Managed or Autonomous beacon (support for OBC failure),

- Data stream (uplink and downlink),

- Antenna deploy support.

The SPINO board also features functions dedicated to the amateur radio community with a versatile digital transponder and a digital mailbox service.

The SPINO payload will be a pre-validated open source brick available off the shelf for any CubeSat mission. By the way, the goal is to maximize compatibility (standardized interfaces with UART, I2C, SPI, controller area network flexible data-rate, and standardized PC-104 form factor), and maximize reliability (wide supply voltage range, fail-safe on key points, low power consumption, especially in idle to face failure situations).

SPINO operates in the Amateur Radio service bands, and features two full transceivers:

- VHF: TX (+30 dBm) and RX 144-146 MHz,

- UHF: TX (+30 dBm) and RX 430-440 MHz.

For this particular operation, SPINO SC will be 'locked' on the 'TX UHF/RX VHF' mode (requested frequencies: i.e., UHF $435.200 \mathrm{MHz}$ and VHF $145.830 \mathrm{MHz}$ ). In particular, VHF TX path will be unpopulated for safety reasons.

This mission, designed in cooperation with the LATMOS laboratory, is a key point for the project. The 'in-flight' validation will allow SPINO to be seriously considered as a relevant solution for future missions.

Furthermore, the INSPIRE-SAT 7 mission will provide a new LATMOS FM amateur radio transponder (LAT 2) similar to that used on board UVSQ-SAT (LAT 1). The transponder mode works in the amateur-satellite service allocations of $145.8-146 \mathrm{MHz}$ (uplink) and $435-438 \mathrm{MHz}$ (downlink). The single channel FM transponder can be used by radio amateurs to communicate with each other via the CubeSat. The transponder offers a 'squelch' functionality whereby it only activates after the received signal strength reaches a certain user-programmable threshold.

Experience feedback from the UVSQ-SAT mission shows that the audio transponder cannot be used permanently (integrity of the equipment, power budget). To overcome this, the INSPIRE-SAT 7 mission will embark a new amateur radio payload (SPINO) so that it can be permanently operational.

\subsubsection{The INSPIRE-SAT 7 IMU}

The IMU sensor $(50 \times 25 \times 10 \mathrm{~mm}, 30 \mathrm{~g}, 60 \mathrm{~mW}$ OAP) is based on an inertial measurement unit. It uses a 3-axis accelerometer, a 3-axis gyroscope, and a 3-axis compass that will measure the magnetic fields in three directions. IMU is an improved 3-axis accelerometer/gyroscope/compass, which will be used for determining the attitude of the INSPIRE-SAT 7 CubeSat. Main expected IMU sensor technical requirements are in Table 6.

\subsection{The Ground Segment-The UHF/VHF Station}

For the UVSQ-SAT mission, a LATMOS ground station system has been set up [1]. It is fully operational. To have redundancy, an INSPIRE-SAT 7 ground station will be set up by LATMOS. Figures 5 and 6 show the new configuration.

The INSPIRE-SAT 7 CubeSat will use satellite amateur radio frequency bands (i.e., VHF $145.970 \mathrm{MHz}$ and UHF $437.410 \mathrm{MHz}$ ). An international frequency coordination is under preparation (F4IXO and F4IXT) with the help of the local Radio-Club (F6KRK, France) and the AMSAT-Francophone for being submitted to IARU.

INSPIRE-SAT 7 represents a good way to interest young people in space and radiofrequency activities. This is also an excellent support for hands-on experience to our students. 
3.4. INSPIRE-SAT 7 Mission Concept of Operations and Calibration and Validation (Cal/Val)

INSPIRE-SAT 7 mission concept of operations (ConOps) phases will be close to those used in UVSQ-SAT [1]. There are four distinct ConOps phases:

- Operations before launch and launch,

- Launch early operations and satellite platform in-orbit verification,

- Instrument in-orbit verification and operations calibration/validation (Cal/Val) of the instruments payload,

- $\quad$ End of life of the INSPIRE-SAT 7 CubeSat.

Table 6. INSPIRE-SAT 7 IMU technical requirements.

\begin{tabular}{ll}
\hline Parameter & Requirements \\
\hline IMU signal range & Accelerometer: $\pm 2.0 \mathrm{~g}$ \\
& Gyroscope: $\pm 250.0 \mathrm{deg}$ \\
IMU resolution & Compass: $\pm 491.2 \mu \mathrm{T}$ \\
IMU noise detection & 16 bits \\
& Accelerometer: $<250 \mu \mathrm{g} / \sqrt{\mathrm{Hz}}$ \\
IMU time response & Gyroscope: $<0.02 \mathrm{deg} / \mathrm{s} / \sqrt{\mathrm{Hz}}$ \\
Acquisition integration time & $<20 \mathrm{~ms}$ \\
\hline
\end{tabular}

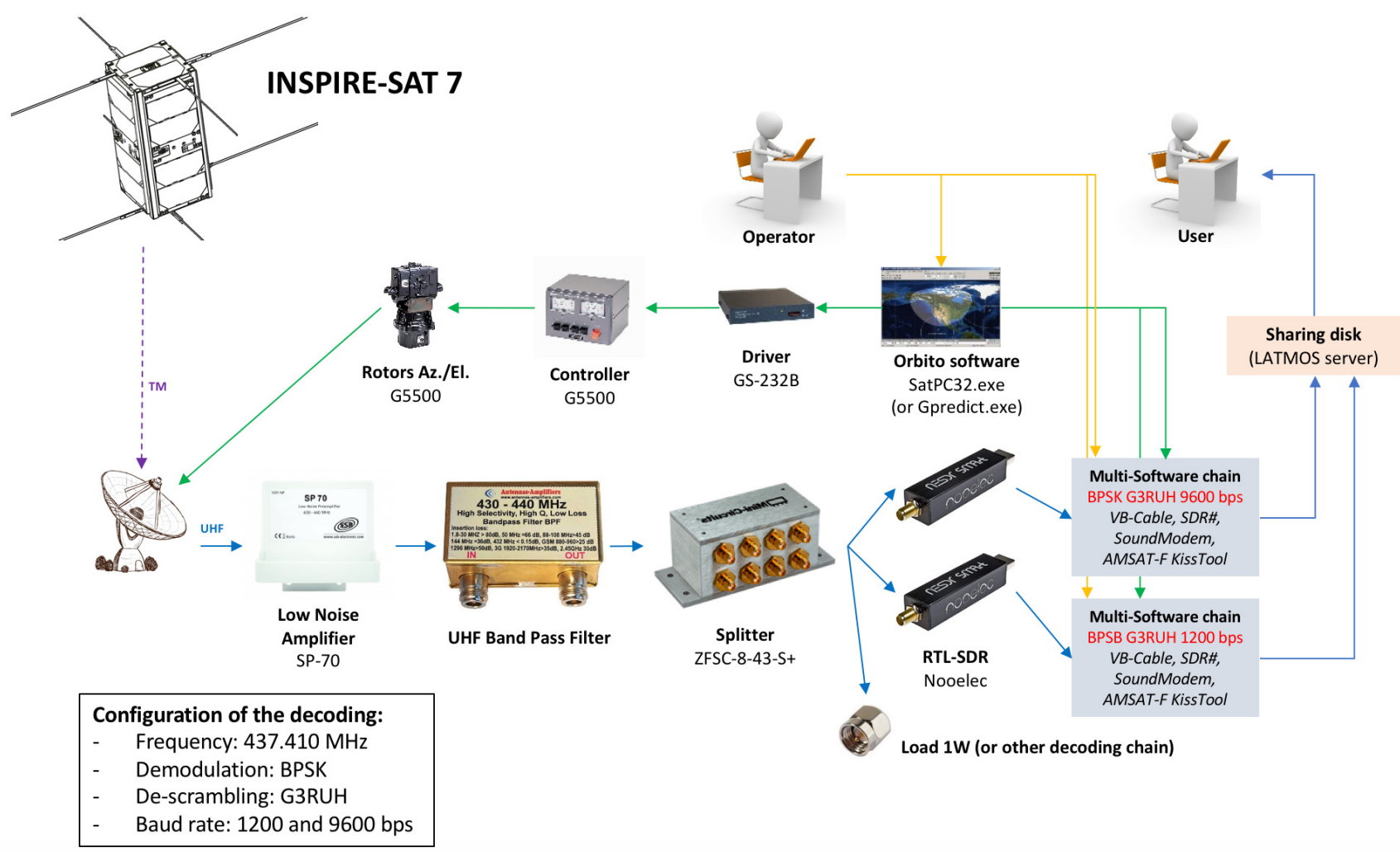

Figure 5. INSPIRE-SAT 7 downlink configuration. 


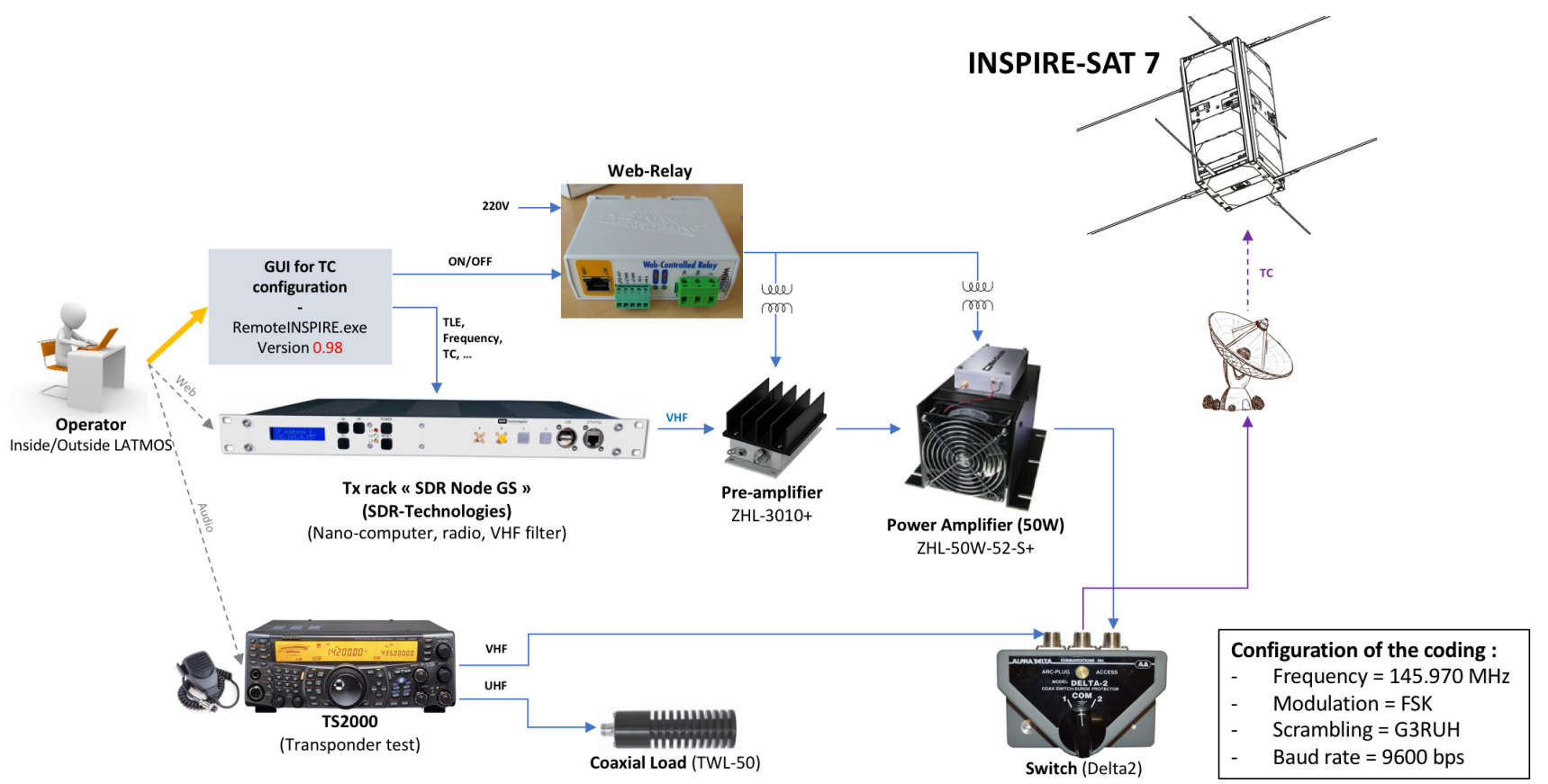

Figure 6. INSPIRE-SAT 7 uplink configuration.

Based on our experience of the UVSQ-SAT mission, an automatic procedure will be programmed on board INSPIRE-SAT 7 for early operations. The following chronology will be implemented:

- Separation of INSPIRE-SAT 7 from the launcher. Automatic platform start-up in 'INIT' mode.

- $\quad \mathrm{T} 0+15$ min: Sequence of deployment of telecommunication antennas (INSPIRE-SAT 7 platform).

- $\quad \mathrm{T} 0+30 \mathrm{~min}$ : Sequence of deployment of the CUIONO1 payload antennas (INSPIRESAT 7 payload).

- T0 + 40 min: Switch to 'Detumbling' mode-iMTQ board On during 5 min to stabilize the CubeSat.

- $\quad \mathrm{T} 0+45$ min: Switch to 'Stand-by mode' and waiting for the first tele-command (TC) from the LATMOS ground station.

- If after 4 days, no TC is received by the CubeSat, the initialization procedure is restarted in 'debugging' mode (deployment of the telecommunication antennas). And this every 4 days until receipt of the first TC.

- T0 + 4 days: Switch to 'Nominal mode' using a TC from LATMOS ground station. Three phases of cal/val are foreseen for INSPIRE-SAT 7:

- A pre-launch phase instruments characterizations and on-ground calibration. Several tests are planned to determine with accuracy the pre-flight absolute uncertainty of scientific variables of interest for the INSPIRE-SAT 7 mission (OSR, OLR, TSI, UV SSI). A first pre-flight absolute calibration of each ERS sensor will be done with the LATMOS BX-500 blackbody, which offers a wide field of view for the calibration of the sensors. The blackbody (diameter of $57 \mathrm{~mm}$, emissivity of 0.95 , minimum distance with the sensors of around $40 \mathrm{~mm}$ ) will be operated at several set-point increments of $5 \mathrm{~K}$ from $323 \mathrm{~K}$ to $343 \mathrm{~K}$. The pre-flight absolute calibration of each ERS sensor will also be carried out with the BB 3200 pg (as pyrolytic-graphite) blackbody of PhysikalischTechnische Bundesanstalt (Germany) as primary standard [19,20]. The BB $3200 \mathrm{pg}$ blackbody (opening area of $111.4 \mathrm{~mm}^{2}$, minimum distance with the sensors of around $700 \mathrm{~mm}$ ) will be operated at several temperatures between $2800 \mathrm{~K}$ and $3150 \mathrm{~K}$. Finally, the INSPIRE-SAT 7 CubeSat will be integrated into the LATMOS/OVSQ INTRA Solar Tracker $\left(0.038^{\circ}\right.$ resolution) to calibrate the ERS sensors in visible bands toward the 
Sun. Ground-based pyranometers (Kimo SAM30 (400 to 1100 nm, unidirectional, 1 to $1300 \mathrm{Wm}^{-2}$ ) and Kipp \& Zonen SMP6-V (270 to $3000 \mathrm{~nm}$, field of view of $180^{\circ}$, 0 to $1600 \mathrm{Wm}^{-2}$ with an uncertainty of $\left.\pm 20 \mathrm{Wm}^{-2}\right)$ ) will also be integrated on the solar tracker to provide an independent measurement of the solar flux that could be compared to that measured by the ERS sensors. From these different tests led by LATMOS, a pre-flight absolute uncertainty close to $\pm 5 \mathrm{Wm}^{-2}(1 \sigma)$ is expected for OSR and OLR.

A pre-flight absolute calibration of the TSIS sensors will be done with a LATMOS test bench that simulates an artificial Sun (Newton telescope (focal of $1410 \mathrm{~mm}$, diameter of $20 \mathrm{~cm}$, image field of $0.5^{\circ}$ ), Xenon arc lamp (model 6269) of $1000 \mathrm{~W}$ where the Xenon lines dominate between 750 and $1000 \mathrm{~nm}$, but the spectrum is almost featureless through the ultraviolet and visible). A pre-flight absolute calibration will also be done with the INTRA Solar Tracker. From these different tests led by LATMOS, a pre-flight absolute uncertainty close to few \% is expected for TSI.

A pre-flight absolute calibration of the UVS sensors will be done with a LATMOS test bench (Stellarnet SL3 deuterium light source (UV for the 190-450 nm range, power output of $15 \mathrm{Wm}^{-2}$ ), chopper, scanning monochromator Optometrics SDMC1-01, Keithley 2450 sourcemeter (I-ranges of $10 \mathrm{nA}$ to $1 \mathrm{~A}, 0.012 \%$ of accuracy)). Finally, the UV-VIS BIRA-IASB facilities will be used for the calibration of the UVS sensors. This facility delivers a monochromatic and tunable light beam produced by a combination of a double monochromator, and different lamps (UV arc lamp, solar simulator, tungsten lamp). The output monochromatic light can be collimated or injected in a large $(\sim 30 \mathrm{~cm})$ integrating sphere for spectral response characterization or flat field measurements. From these different tests led by LATMOS and BIRA-IASB, a pre-flight absolute uncertainty close to few \% is expected for UV SSI.

No direct on-orbit calibration is possible because the CubeSat is too small to integrate in-flight calibration sources. For ERS sensors, we use carbon nanotubes that are not subject to aging in orbit. The aging of these sensors is considered as weak. However, payload electronics can undergo aging in orbit. Thus, standard (etalon) currents have been integrated into the INSPIRE-SAT 7 payload printed circuit board to check the stability of the sensors electronic (ERS, TSIS, UVS). In the future, we wish to use sources of gallium (melting point of $302.91 \mathrm{~K}$ ) to monitor the aging of ERS sensors for example.

- A commissioning phase lasting approximately 1 month will be performed for INSPIRESAT 7 where all instrument operation aspects will be verified and in-orbit calibration and validation activities will be initiated with a validation of the 3-axis accelerometer/gyroscope/compass inertial measurement unit, a determination of the magnetic field of the Earth, a determination of the attitude of the satellite using the TRIAD and MEKF methods, a determination of the flux measured by the sensors (OSR, OLR, TSI, UV SSI), and a technological validation of the different instruments (Li-Fi payload led by LATMOS and Oledcomm, CUIONO1 payload led by ONERA, SPINO payload led by LATMOS and Adrelys).

- An exploitation phase that will extend for the duration of the mission in which calibration and validation activities will continue with the main goal to obtain the main scientific data products. A quantification of the instruments aging will be done. Possible corrections will be carried out.

\section{UVSQ-SAT CubeSat Observations in Orbit and Future Observations (INSPIRE-SAT 7, Terra F)}

\subsection{UVSQ-SAT Real Observations and INSPIRE-SAT 7 Simulated Observations}

In January 2021, the UVSQ-SAT CubeSat was launched into orbit with a SpaceX Falcon 9 rocket from Cape Canaveral in Florida (United States). In the CubeSat's early hours post-launch, the dedicated flight control team at LATMOS operations centre in Guyancourt (78, France), took meticulous care of UVSQ-SAT in what is known as the launch and early 
orbit phase. 'First-light' measurements from UVSQ-SAT were obtained on February 2021, with first observations of OSR and OLR [2]. The 'routine' mode was activated on 13 March 2021. Now, months later, the CubeSat has successfully passed what is known as the 'inorbit verification phase', where its scientific payload is switched on and the instruments' performance is checked. All satellite subsystems are working in perfect order. As of this writing, UVSQ-SAT continues to operate normally in orbit at an altitude of $\sim 534 \mathrm{~km}$.

The time series obtained with UVSQ-SAT since the beginning of its operational phase in February 2021 allow the construction of OSR and OLR flux maps from the measurements made by the sensors onboard the satellite. An example of UVSQ-SAT observations is given in Figure 7c,f for the month of August 2021. It is based on UVSQ-SAT Level-1 data products (version 1.0), and requires additional data processing to improve the measurements (particularly for OLR). These maps highlight the scientific relevance of the technological choices for the study of essential climate variables at the TOA.

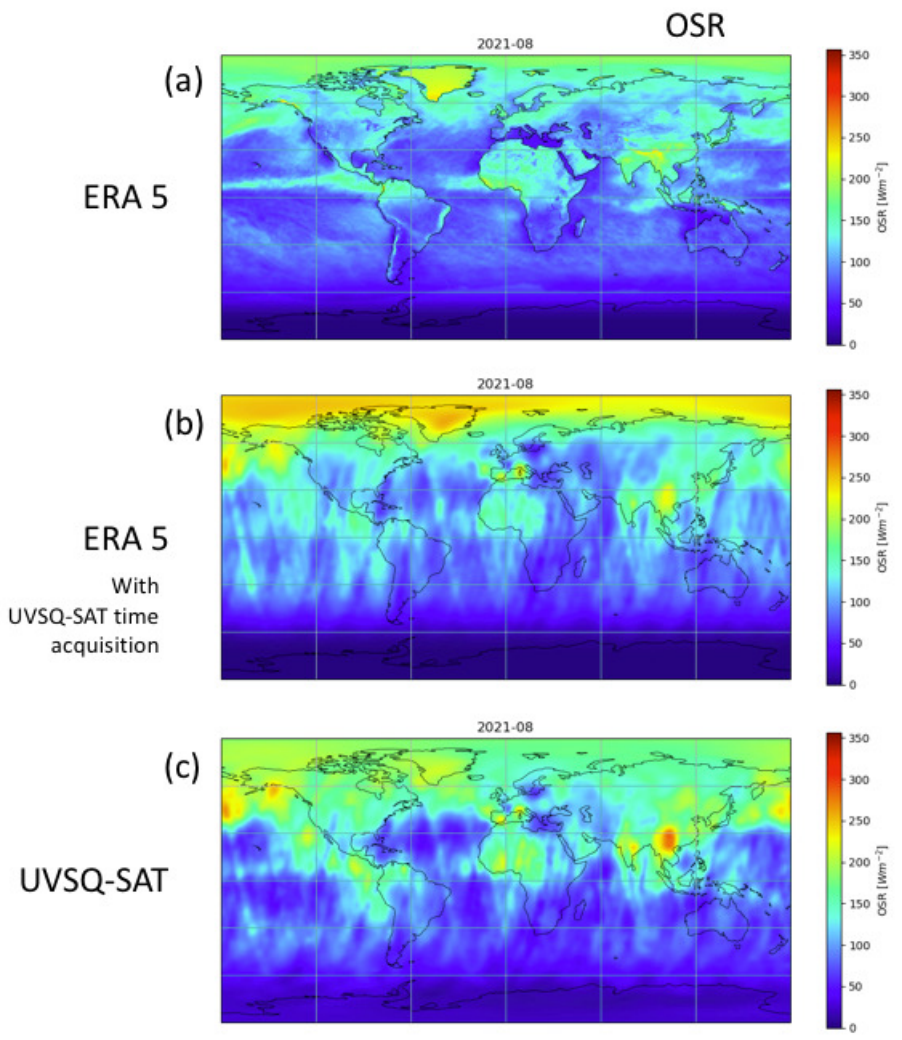

(d)

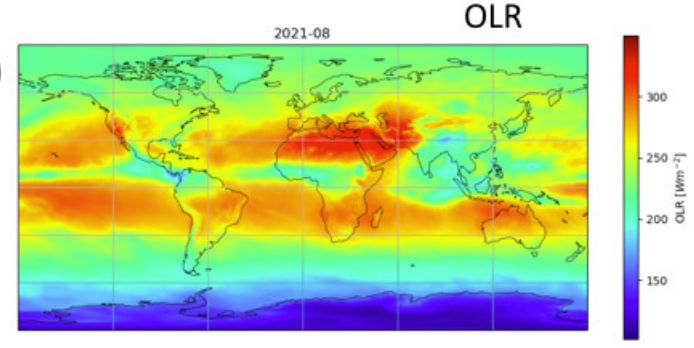

(e)

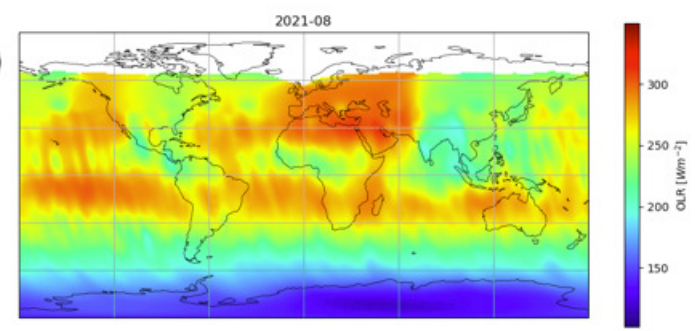

(f)

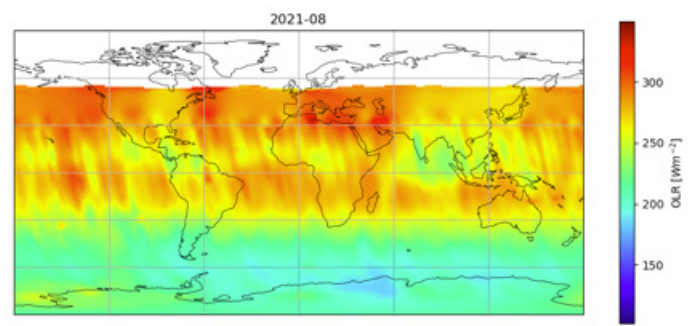

Figure 7. (a) TOA outgoing shortwave radiation from ERA 5 model. $1^{\circ} \times 1^{\circ}$ latitude by longitude. Monthly averaged. (b) TOA outgoing shortwave radiation from ERA 5 model with UVSQ-SAT data time acquisition. (c) TOA outgoing shortwave radiation from UVSQ-SAT observations in August 2021. (d) TOA outgoing longwave radiation from ERA 5 model. $1^{\circ} \times 1^{\circ}$ latitude by longitude. Monthly averaged. (e) TOA outgoing longwave radiation from ERA 5 model with UVSQ-SAT data time acquisition (eclipse period). (f) TOA outgoing longwave radiation from UVSQ-SAT observations in August 2021 (eclipse period).

The map reconstruction method from UVSQ-SAT time series is described in [2]. It is based on the consideration that the flux measured by UVSQ-SAT results from the different contributions of the region observed by the satellite at a given time. Thus, to reconstruct the flux maps from the time series, we need to determine retrospectively the contribution of each point of the map at each measurement point. As detailed in [2], we consider a Gaussian distribution function that depends on the satellite field of view and associates a weight to each point of the map. The weight associated to each point represents the satellite passage density and depends, in addition to the field of view, on the orbital characteristics 
and the view angle under which the satellite is seen from the surface. This method can be applied to both UVSQ-SAT observations and the ERA-5 model. In the case of the ERA-5 model, the satellite ground-track is used and the time series are simulated by considering the contribution of each point to the measurement according to the method described just before.

OSR and OLR time series are derived from the measurements made by the various sensors on board the CubeSat and from in-orbit attitude knowledge. New methods were developed to obtain UVSQ-SAT in-orbit attitude knowledge using Tri-Axial Attitude Determination (TRIAD) and Multiplicative Extended Kalman Filter (MEKF) methods [16]. The different inputs available to the algorithms are three-axis angular velocities (UVSQ-SAT gyrometer), six-axis solar direction (UVSQ-SAT photodiodes in the visible domain), and three-axis magnetic field (UVSQ-SAT magnetometer). In sunlight, the CubeSat attitude is obtained with an accuracy better than $3^{\circ}$ (at one $\sigma$ ) for both methods. During eclipses, the accuracy of the TRIAD method is $14^{\circ}$, while it reaches $10^{\circ}$ (at one $\sigma$ ) for the recursive MEKF method. A reduction in CubeSat attitude knowledge uncertainties would improve the UVSQ-SAT results (OSR and OLR). Finally, it is possible to generate flux maps at TOA for the desired time step. Figure 7 shows monthly averaged maps for $\operatorname{OSR}(a, b, c)$ and OLR at TOA (d, e, f) for the month of August 2021 (simulation, UVSQ-SAT, INSPIRE-SAT 7 projection). Three cases are considered:

- Comparisons with the ERA 5 model (a,d). ERA 5 is produced by the Copernicus climate change service at the European Centre for Medium-Range Weather Forecasts (ECMWF). ERA 5 is a combination of past observations with models to generate consistent time series of multiple climate variables. It is the fifth-generation reanalysis for the global climate and weather [21]. The purpose of that new dataset was to replace the ERA-Interim, that was implemented in 2006 and was stopped in August 2019. The different objectives of that new implementation were to improve the spatio-temporal resolution, to allow uncertainty estimate, and to add new inputs to the large list. It now reaches a spatial resolution up to $0.25^{\circ} \times 0.25^{\circ}$ with hourly maps around the whole globe. The ERA 5 model is used to provide OSR and OLR at TOA for a given period (average over a month of data, for example).

- $\quad$ Simulated maps using the ERA 5 model as seen by UVSQ-SAT along its track (b,e). These maps are obtained from the determination of the real UVSQ-SAT ground track as a function of time. This ground track is calculated from the two-line element set. Once the position (latitude, longitude) of the UVSQ-SAT CubeSat is determined from ground track, OSR and OLR at TOA time series are obtained from ERA 5 as they would be observed by the UVSQ-SAT CubeSat in orbit (field of view, altitude). OSR and OLR maps are reconstructed from these time series for a given period.

- $\quad$ Reconstructed maps from observations made by UVSQ-SAT (c, f). The reconstructed method from observations is explained in detail in [2]. This method is used to provide UVSQ-SAT OSR and OLR at TOA for a given period.

Qualitatively, we observe in the case of OSR an excellent agreement between the model and the observations that is encouraging for the future INSPIRE-SAT 7 perspective. Particularly, the radiation structures are identifiable for different geographic areas such as Europe and Northern Africa, Northern South America, Greenland, Alaska and Southeast Asia. For OLR, the reconstruction allows to obtain the main trends. However, the ground track of the UVSQ-SAT CubeSat is still visible, which can be improved by increasing data sampling.

Figure 8 provides a quantitative analysis of the temporal evolution of OSR (left) and OLR (right) between February and August 2021. The curves are obtained by simply averaging (weighted by pixel size) the UVSQ-SAT observations (magenta), the ERA 5 model (blue), and the observations simulated from the ERA 5 model (black and red). The average monthly fluxes of OSR and OLR follow the same trend for the observations simulated with the ERA 5 model (black) and the UVSQ-SAT observations (magenta). There is a bias between the model and the observations of about $6 \mathrm{Wm}^{-2}$ in the case of OSR and 
around $20-25 \mathrm{Wm}^{-2}$ in the case of OLR. The biases can be explained by limits linked to the ground-based calibrations of the UVSQ-SAT instruments. However, they remain compatible with the requirements set out in Table 1 (absolute accuracy of $\pm 10.00 \mathrm{Wm}^{-2}$ for OSR and OLR). The absolute determination of the ERB parameters requires rigorous calibrations including pre-flight calibration compatible with international standards, and in flight-calibration to monitor aging with same process. The size of CubeSats and the use of broadband non-scanner instruments could represent a limit. The implementation of a future constellation (Terra-F) requires a mastery of calibrations to guarantee the absolute determination of top of atmosphere global net radiation budget.

Moreover, the different trends for the average ERA 5 model come from the fact that the satellite is on a Sun-Synchronous orbit at a constant LTDN, while the model is averaged over the whole month without distinction of local times.

This last point underlines the importance of a satellite constellation placed in SunSynchronous orbits at different local times to provide a regular spatial and temporal coverage. In Figure 8, the simulation of the OSR and OLR trends for a two-CubeSats constellation (INSPIRE-SAT 7) illustrates the improvement obtained. In this simulation, the first satellite has the same orbital parameters as UVSQ-SAT with a Sun-Synchronous orbit at 21:30 LTDN. The second satellite has an equivalent orbit, but at 09:30 LTDN. The simulated trends are very close to the average ERA 5 model.
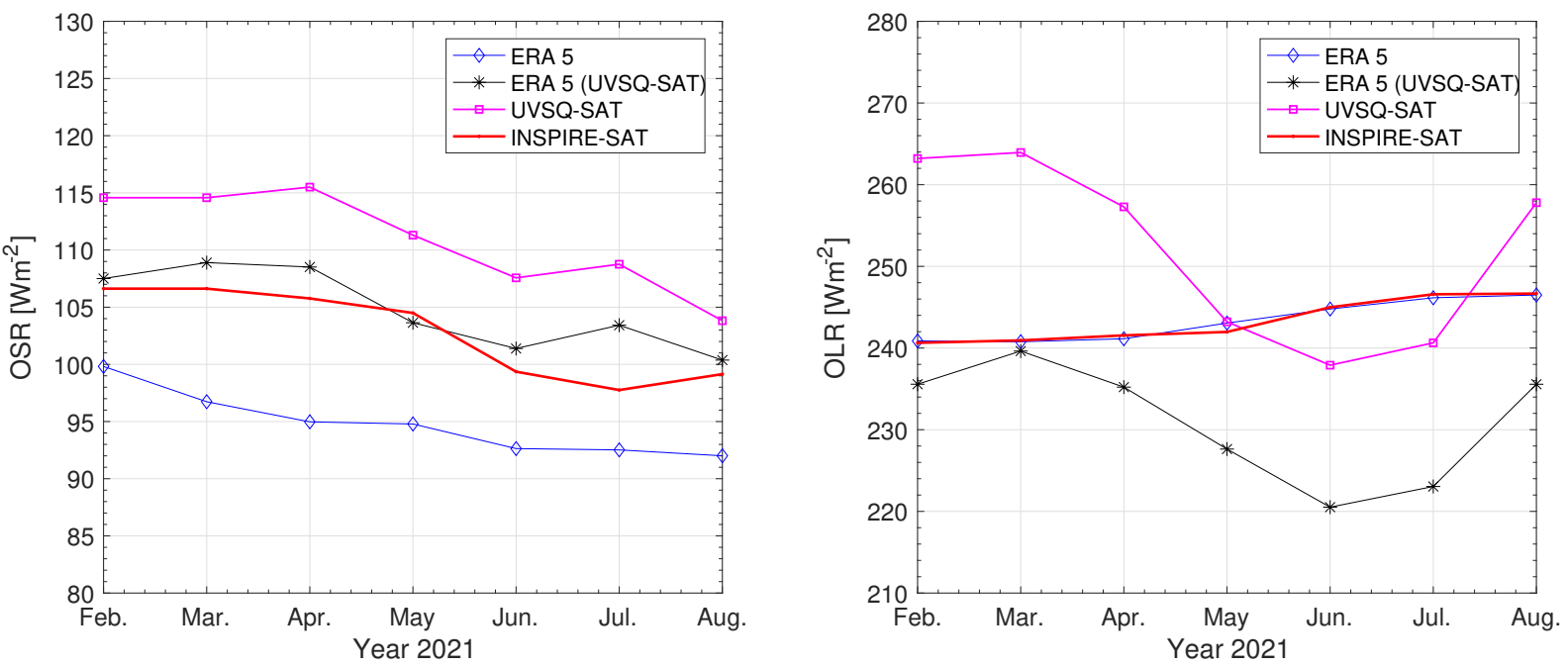

Figure 8. (left) Monthly time series of the TOA outgoing shortwave radiation of ERA 5, ERA 5 model with UVSQ-SAT data time acquisition, UVSQ-SAT (data in orbit), and INSPIRE-SAT 7 (simulation). (right) Monthly time series of the TOA outgoing longwave radiation of ERA 5, ERA 5 model with UVSQ-SAT data time acquisition, UVSQ-SAT (data in orbit), and INSPIRE-SAT 7 (simulation).

Figure 9 shows the result of the reconstruction after a few iterations of the simulation in the case of OSR. It shows the temporally interpolated map of the ERA 5 model at the time of the measurement (top left), the averaged ERA 5 map (top right), the simulated map considering the field of view characteristics of the UVSQ-SAT sensors (bottom left) and the difference between the simulation and the averaged ERA 5 map (bottom left).

\subsection{The Terra-F Constellation}

It is crucial to determine the characteristics of a satellite constellation that meet the scientific requirements in the ERB monitoring (Table 1). We developed a simulation to obtain the characteristics of the Terra-F satellite constellation. The first step of the simulation is to define the number of satellites, the orbital parameters, and the fields of view of satellite instruments. Orbital parameters can be determined directly from supplied two-line element files. The second step of the simulation is to calculate the ground track of each satellite to obtain its coordinates (latitude, longitude) at each time. The altitude of each satellite is 
also considered in the analysis. It is necessary to define the start date, the duration as well as the time step between two expected measurement points for the simulation. To these two steps, we add the initialization of the ERA 5 model that will be used for simulate the ERB observations. Once the initialization has been carried out, the OSR and OLR maps are reconstructed from the time series of ground track calculated previously for each satellite of the constellation.

Figure 10 shows an example of results obtained from simulations. This illustrates one of the issues related to the CubeSat constellation, namely the temporal (left) and spatial (right) resolutions that can be achieved depending on the characteristics of the constellation (Terra-F) and the sensors on board. The challenge is to find the good compromise between temporal resolution, which improves when the FOV increases while spatial resolution improves when the FOV decreases. Signal processing methods can be also considered to improve the spatial resolution.
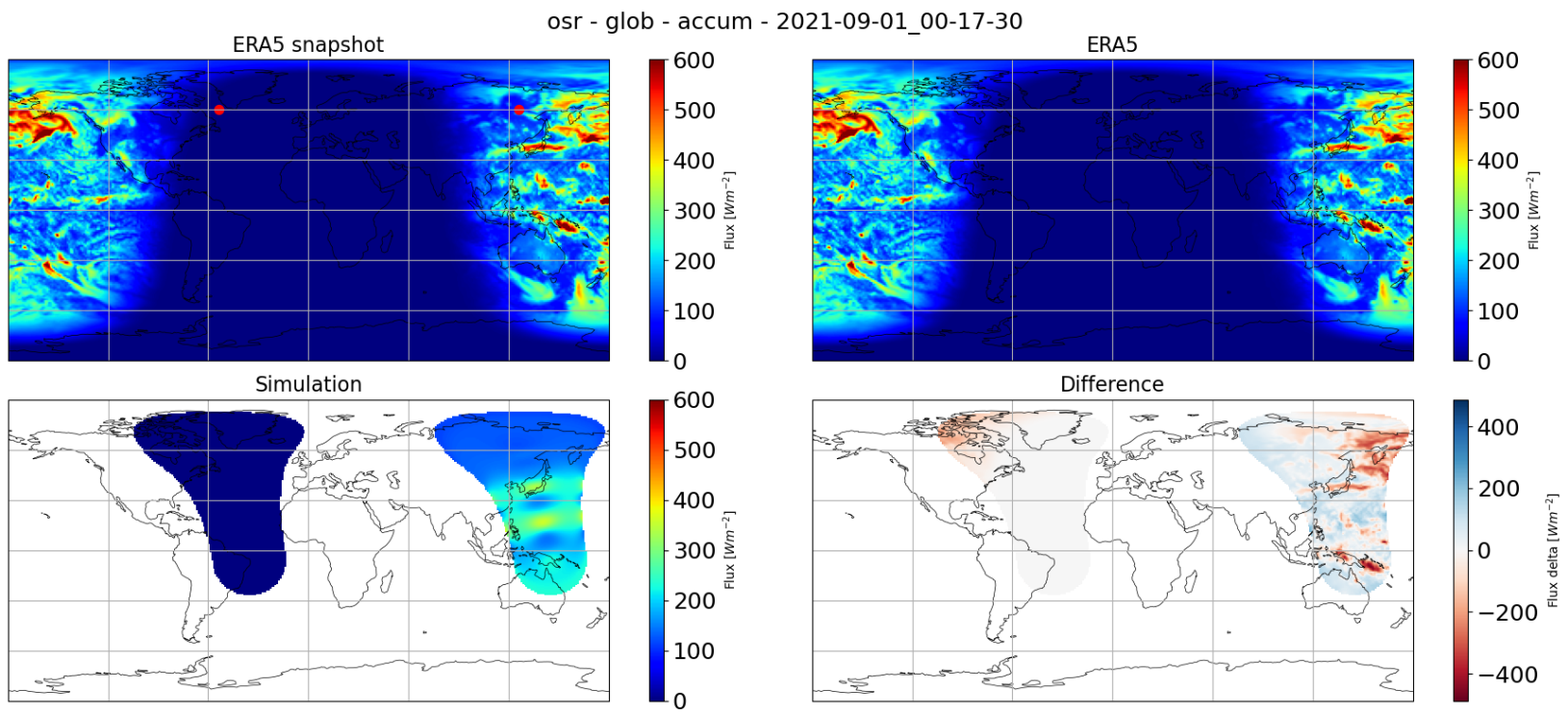

Figure 9. First steps of the simulation of two satellites in orbit (UVSQ-SAT and INSPIRE-SAT 7) to restore the flux of the Earth at the top-of-the-atmosphere.
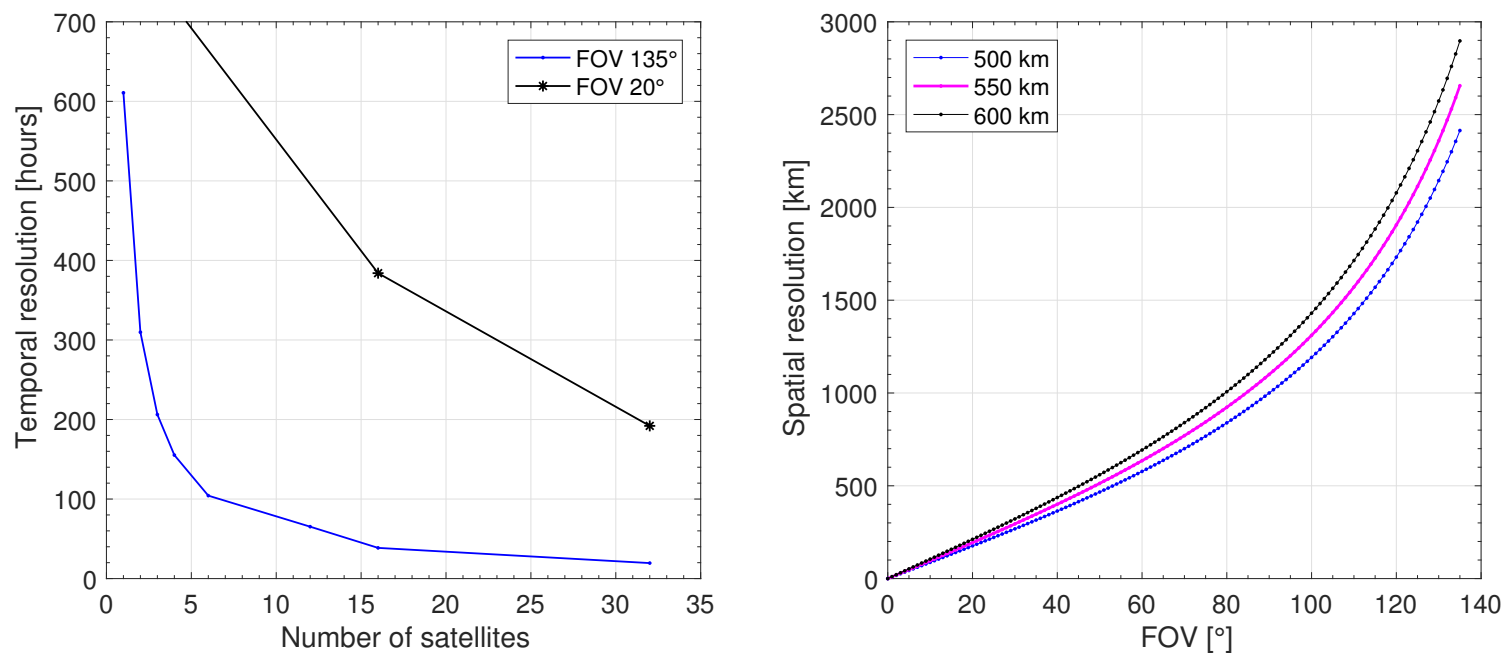

Figure 10. (left) Estimation of the number of satellites (constellation) according to the temporal resolution. (right) Influence of field of view (FOV) on spatial resolution for three CubeSats altitude.

Figure 11 shows a possible small satellite constellation (Terra-F ) based on 32 satellites that evolve on 8 orbital planes. It meets the requirements presented in Table 1 (temporal 
resolution of three hours). The characteristics of such satellite constellations to meet scientific requirements and monitor essential climate variables will be the subject of a forthcoming manuscript.

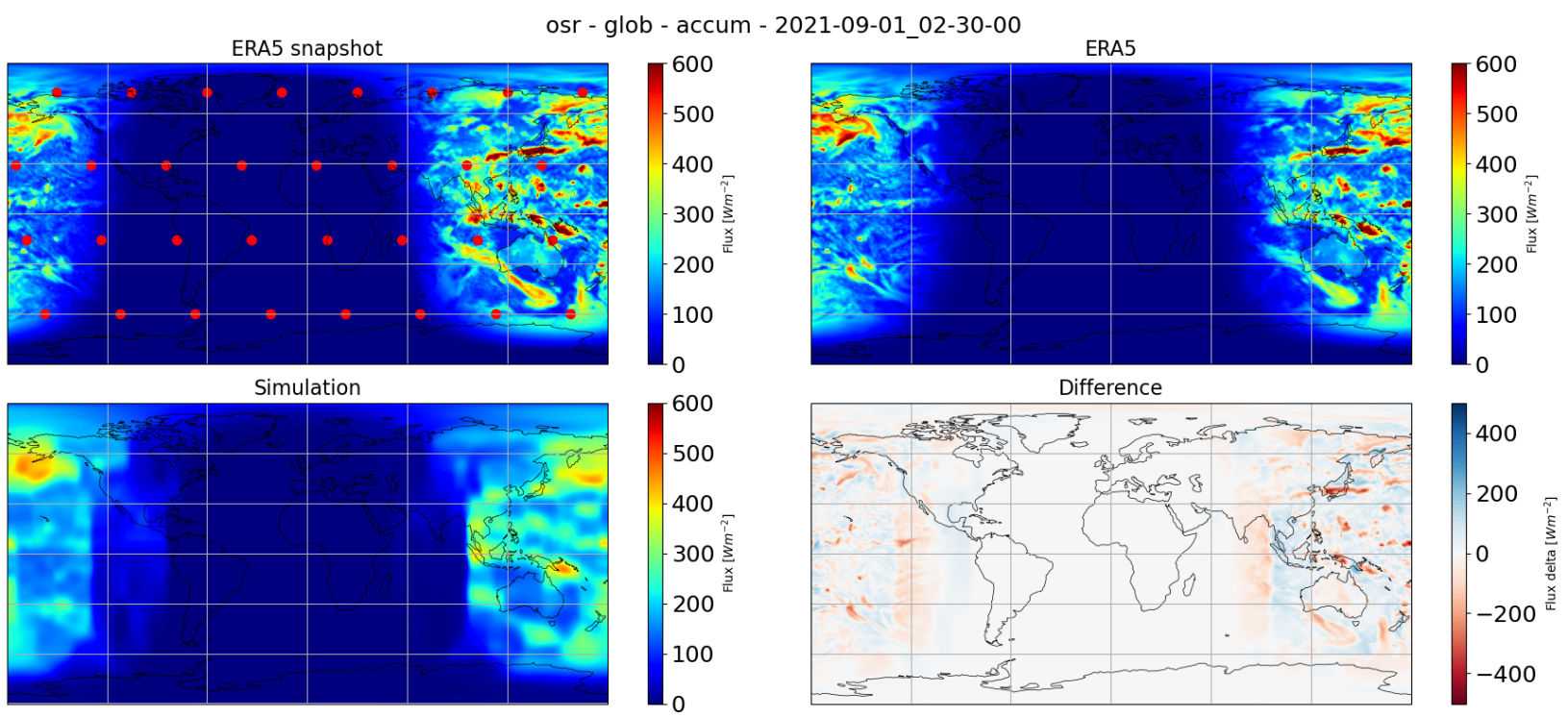

Figure 11. Terra-F constellation of 32 satellites that evolve on 8 orbital planes.

\section{Conclusions}

INSPIRE-SAT 7 is a scientific and in-orbit technological demonstration satellite in the domain of Earth Observation (ERB and ionospheric measurements) and Solar Physics (total and solar spectral irradiance), scheduled to be launched in 2023. INSPIRE-SAT 7 uses disruptive technologies for remote sensing and will improve the miniaturization and compactness of small sensors onboard small satellites.

The results obtained with UVSQ-SAT are encouraging. They pave the way for the future INSPIRE-SAT 7 mission, which will have to work in concert with the UVSQ-SAT mission. We show how two CubeSats in orbit could improve the ERB measurements. With INSPIRE-SAT 7, we hope to improve the absolute accuracy $\left( \pm 5.00 \mathrm{Wm}^{-2}\right.$ for OLR and OSR), the stability per year $\left( \pm 1.00 \mathrm{Wm}^{-2}\right.$ for OLR and OSR), and the temporal resolution (10 days with 2 CubeSats in-orbit). About spatial resolution, it is not possible to obtain improvements with only 2 CubeSats in low Earth orbit using sensors with a wide field of view. It would be necessary to have sensors with fields of view of at most $10^{\circ}$ to obtain a spatial resolution close to $100 \mathrm{~km}$. Our analysis shows the interest of developing a constellation of at least 32 satellites evolving in multiple orbital path with sensors using narrow and wide field of view to respect the Terra-F requirements (temporal and spatial resolutions).

Finally, the INSPIRE-SAT 7 tools are used in our education program to train students in space technology, Earth observations, and Astronomy \& Astrophysics. INSPIRE-SAT 7 is part of the INSPIRE program, which is an international consortium of Universities collaborating in science and small satellites development.

Author Contributions: Conceptualization (D.B., C.B. (Catherine Billard)), LATMOS (M.M., P.K., A.S., T.B., S.B., L.D., P.G. (Patrick Galopeau), A.H. (Alain Hauchecorne), C.D. (Christophe Dufour), A.F., A.-J.V., E.B., P.G. (Pierre Gilbert), N.C., C.D. (Clément Dias), J.-L.E., P.L.), ONERA (F.B., K.G., V.R., S.S.), ACRI-ST (V.S., A.M.), Adrelys (Y.A.), Oledcomm (B.A., C.B. (Cyril Brand), C.D. (Carlos Dominguez)), ISIS (A.H. (Akos Haasz), A.P., K.S.), PIT (P.M., S.A.), AMSAT-Francophone (C.M.); science (climate studies, solar physics, ionosphere), LATMOS (M.M., P.K., A.S., S.B., L.D., P.G. (Patrick Galopeau), A.H. (Alain Hauchecorne)), ONERA (F.B., K.G., V.R., S.S.); hardware and engineering, LATMOS (M.M., A.-J.V., E.B., P.G. (Pierre Gilbert), N.C., C.D. (Clément Dias), J.-L.E., P.L.), ONERA (F.B., K.G., V.R., S.S.), Adrelys (Y.A.), Oledcomm (C.B. (Cyril Brand), C.D. (Carlos Dominguez)), ISIS (A.H. (Akos Haasz), A.P., K.S.); methodology, LATMOS (M.M.); software, LATMOS (M.M., P.K., A.S., 
T.B., S.B., L.D., P.G. (Patrick Galopeau), A.H. (Alain Hauchecorne), C.D. (Christophe Dufour), A.F.); formal analysis, LATMOS (M.M., P.K., A.S., T.B., S.B., L.D., P.G. (Patrick Galopeau), A.H. (Alain Hauchecorne), C.D. (Christophe Dufour), A.F.); resources, LATMOS (M.M., P.K., A.S., T.B., S.B., L.D., P.G. (Patrick Galopeau), A.H. (Alain Hauchecorne), C.D. (Christophe Dufour), A.F., A.-J.V., E.B., P.G. (Pierre Gilbert), N.C., C.D. (Clément Dias), J.-L.E., P.L.), ONERA (F.B., K.G., V.R., S.S.), ACRI-ST (V.S., A.M.), Adrelys (Y.A.), Oledcomm (B.A., C.B. (Cyril Brand), C.D. (Carlos Dominguez)), ISIS (A.H. (Akos Haasz), A.P., K.S.), PIT (P.M., S.A.), AMSAT-Francophone (C.M.); writing-original draft preparation, LATMOS (M.M., P.K., A.S., T.B., S.B., L.D., P.G. (Patrick Galopeau), A.H. (Alain Hauchecorne), C.D. (Christophe Dufour), A.F., A.-J.V., E.B., P.G. (Pierre Gilbert), N.C., C.D. (Clément Dias), J.-L.E., P.L.), ONERA (F.B., K.G., V.R., S.S.), ACRI-ST (V.S., A.M.), Adrelys (Y.A.), Oledcomm (B.A., C.B. (Cyril Brand), C.D. (Carlos Dominguez)), ISIS (A.H. (Akos Haasz), A.P., K.S.), PIT (P.M., S.A.), AMSAT-Francophone (C.M.); writing-review and editing, LATMOS (M.M., P.K., A.S., T.B., S.B., L.D., A.F.), and ONERA (F.B., K.G., V.R., S.S.); project administration, LATMOS (M.M.); funding acquisition, LATMOS (M.M.), ONERA (F.B.), ACRI-ST (A.M.), Adrelys (Y.A.), Oledcomm (B.A.). All authors have read and agreed to the published version of the manuscript.

Funding: This research was mainly funded by Centre National de la Recherche Scientifique (CNRS, France), UVSQ (Université de Versailles Saint-Quentin-en-Yvelines, France), Agence Nationale de la Recherche (ANR, France), Office National d'Etudes et de Recherches Aérospatiales (ONERA, France), Développement économique-Saint-Quentin en Yvelines (78, France), and Département des Yvelines (78, France).

Institutional Review Board Statement: Not applicable.

Informed Consent Statement: Not applicable.

Data Availability Statement: Not applicable.

Acknowledgments: The INSPIRE-SAT 7 team acknowledges support from the Universite de Versailles Saint-Quentin-en-Yvelines (UVSQ, France), the Office National d'Etudes et de Recherches Aérospatiales (ONERA, France), the Université Paris-Saclay (France), the Sorbonne Université (SU, France), the Centre National de la Recherche Scientifique (CNRS, France), the Centre National d'Études Spatiales (CNES, France), the Département des Yvelines (78, France), the Laboratory for Atmospheric and Space Physics (Dan Baker, LASP, USA), the National Central University (Loren Chang, NCU, Taiwan), the Nanyang Technological University (Amal Chandran, NTU, Singapore), the South African National Space Agency (Martin Snow, SANSA, South Africa). The authors also thankfully acknowledge the Ministère de l'Enseignement supérieur, de la Recherche et de l'Innovation (MESRI, France) for their support. This work is supported by the Programme National Soleil Terre (PNST, France) of CNRS/INSU (France) co-funded by Centre National d'Études Spatiales (CNES, France) and Commissariat à l'énergie atomique (CEA, France).

Conflicts of Interest: The authors declare no conflict of interest.

\section{Abbreviations}

List of acronyms

$\begin{array}{ll}\text { Acronym } & \text { Definition } \\ \text { ADC } & \text { Analog-to-Digital Converter } \\ \text { ADCS } & \text { Attitude Determination and Control Subsystem } \\ \text { AMSAT } & \text { The Radio Amateur Satellite Corporation } \\ \text { ASIC } & \text { Application-Specific Integrated Circuit } \\ \text { BOL } & \text { Beginning Of Life } \\ \text { CAN FD } & \text { Controller Area Network Flexible Data-Rate } \\ \text { CDHS } & \text { Command and Data Handling Subsystem } \\ \text { CUIONO1 } & \text { Charge Utile IONOsphérique 1 (Ionospheric payload) } \\ \text { DB } & \text { DaughterBoard } \\ \text { ECMWF } & \text { European Centre for Medium-Range Weather Forecasts } \\ \text { ECV } & \text { Essential Climate Variable } \\ \text { EEI } & \text { Earth's Energy Imbalance } \\ \text { EEPROM } & \text { Electrically-Erasable Programmable Read-Only Memory } \\ \text { ERB } & \text { Earth's Radiation Budget }\end{array}$




\begin{tabular}{|c|c|}
\hline ERS & Earth Radiative Sensor \\
\hline FM & Frequency modulation \\
\hline FOV & Field Of View \\
\hline GOES & Geostationary Operational Environmental Satellites \\
\hline GPIO & General Purpose Input/Output \\
\hline GPS & Global Positioning System \\
\hline $\mathrm{HF}$ & High Frequency \\
\hline $\mathrm{I} 2 \mathrm{C}$ & Inter-Integrated Circuit \\
\hline IARU & International Amateur Radio Union \\
\hline IMU & Inertial Measurement Unit \\
\hline iMTQ & ISIS MagneTorQuer \\
\hline INSPIRE & International Satellite Program in Research and Education \\
\hline ISIS & Innovative Solutions In Space \\
\hline LATMOS & Laboratoire ATMosphères, Observations Spatiales \\
\hline LAT-2 & LATMOS FM amateur radio transponder \\
\hline LED & Light-Emitting Diode \\
\hline LEO & Low Earth Orbit \\
\hline LEOP & Launch and Early Orbit Phase \\
\hline Li-Fi & Light Fidelity \\
\hline LTDN & Local Time at Descending Node \\
\hline MEKF & Multiplicative Extended Kalman Filter \\
\hline OAP & Orbit Average Power \\
\hline OBC & OnBoard Computer \\
\hline $\mathrm{OHC}$ & Ocean Heat Content \\
\hline OLR & Outgoing Longwave Radiation \\
\hline OSR & Outgoing Shortwave Radiation \\
\hline OVSQ & Observatoire de Versailles Saint-Quentin-en-Yvelines \\
\hline $\mathrm{PCB}$ & Printed Circuit Board \\
\hline SDR & Software-Defined Radio \\
\hline SNR & Signal to Noise Ratio \\
\hline SPI & Serial Peripheral Interface \\
\hline SSI & Solar Spectral Irradiance \\
\hline SSO & Sun-synchronous Orbit \\
\hline TOA & Top Of the Atmosphere \\
\hline TOTEM & Flight proven high performance SDR platform designed for CubeSats \\
\hline TRIAD & Tri-Axial Attitude Determination \\
\hline TSI & Total Solar Irradiance \\
\hline TSIS & Total Solar Irradiance Sensor \\
\hline TRXVU & Transceiver \\
\hline UART & Universal Asynchronous Receiver-Transmitter \\
\hline UHF & Ultra High Frequency \\
\hline UVS & Ultra-Violet Sensor \\
\hline UVSQ-SAT & UltraViolet and infrared Sensors at high Quantum efficiency onboard a small SATellite \\
\hline VHF & Very High Frequency \\
\hline
\end{tabular}

\section{References}

1. Meftah, M.; Damé, L.; Keckhut, P.; Bekki, S.; Sarkissian, A.; Hauchecorne, A.; Bertran, E.; Carta, J.P.; David, R.; Sadok, A.; et al. UVSQ-SAT, a pathfinder cubesat mission for observing essential climate variables. Remote Sens. 2020, 12, 92. [CrossRef]

2. Meftah, M.; Boutéraon, T.; Dufour, C.; Hauchecorne, A.; Keckhut, P.; Finance, A.; Bekki, S.; Abbaki, S.; Bertran, E.; Damé, L.; et al. The UVSQ-SAT/INSPIRESat-5 CubeSat Mission: First In-Orbit Measurements of the Earth's Outgoing Radiation. Remote Sens. 2021, 13, 1449. [CrossRef]

3. Von Schuckmann, K.; Cheng, L.; Palmer, M.D.; Hansen, J.; Tassone, C.; Aich, V.; Adusumilli, S.; Beltrami, H.; Boyer, T.; CuestaValero, F.J.; et al. Heat stored in the Earth system: where does the energy go? Earth Syst. Sci. Data 2020, 12, $2013-2041$. [CrossRef]

4. $\quad$ von Schuckmann, K.; Palmer, M.D.; Trenberth, K.E.; Cazenave, A.; Chambers, D.; Champollion, N.; Hansen, J.; Josey, S.A.; Loeb, N.; Mathieu, P.P.; et al. An imperative to monitor Earth's energy imbalance. Nat. Clim. Chang. 2016, 6, 138-144. [CrossRef]

5. Loeb, N.G.; Johnson, G.C.; Thorsen, T.J.; Lyman, J.M.; Rose, F.G.; Kato, S. Satellite and Ocean Data Reveal Marked Increase in Earth's Heating Rate. Geophys. Res. Lett. 2021, 48, e93047. [CrossRef] 
6. Hunsucker, R.D. Radio Techniques for Probing the Terrestrial Ionosphere; Physics and Chemistry in Space; Springer: Berlin/Heidelberg, Germany, 1991; Volume 22. [CrossRef]

7. Galkin, I.A.; Khmyrov, G.M.; Kozlov, A.; Reinisch, B.W.; Huang, X.; Kitrosser, D.F. Ionosonde networking, databasing, and Web serving. Radio Sci. 2006, 41, RS5S33. [CrossRef]

8. Friis-Christensen, E.; Lühr, H.; Knudsen, D.; Haagmans, R. Swarm-An Earth Observation Mission investigating Geospace. Adv. Space Res. 2008, 41, 210-216. [CrossRef]

9. Yau, A.W.; James, H.G. CASSIOPE Enhanced Polar Outflow Probe (e-POP) Mission Overview. Space Sci. Rev. 2015, 189, 3-14. [CrossRef]

10. Jin, Y.; Clausen, L.B.N.; Spicher, A.; Ivarsen, M.F.; Moen, J.I. Ionospheric Irregularities in the Cusp Ionosphere: In situ Observations by NorSat-1 Satellite. In Proceedings of the 2020 XXXIIIrd General Assembly and Scientific Symposium of the International Union of Radio Science, Rome, Italy, 29 August-5 September 2020; pp. 1-4. [CrossRef]

11. Liu, T.; Yang, G.; Hu, Y.; Jiang, C.; Lan, T.; Zhao, Z.; Ni, B. A Novel Ionospheric Sounding Network Based on Complete Complementary Code and Its Application. Sensors 2019, 19, 779. [CrossRef] [PubMed]

12. Meftah, M.; Dewitte, S.; Irbah, A.; Chevalier, A.; Conscience, C.; Crommelynck, D.; Janssen, E.; Mekaoui, S. SOVAP/Picard, a Spaceborne Radiometer to Measure the Total Solar Irradiance. Sol. Phys. 2014, 289, 1885-1899. [CrossRef]

13. Meftah, M.; Damé, L.; Bolsée, D.; Hauchecorne, A.; Pereira, N.; Sluse, D.; Cessateur, G.; Irbah, A.; Bureau, J.; Weber, M.; et al SOLAR-ISS: A new reference spectrum based on SOLAR/SOLSPEC observations. Astron. Astrophys. 2018, 611, A1. [CrossRef]

14. Puig-Suari, J.; Schoos, J.; Turner, C.; Wagner, T.; Connolly, R.; Block, R.P. CubeSat developments at Cal Poly: The standard deployer and PolySat. In Small Payloads in Space, Proceedings of the International Symposium on Optical Science and Technology, San Diego, CA, USA, 30 July-4 August 2000; Horais, B.J., Twiggs, R.J., Eds.; SPIE: Bellingham, WA, USA, 2000; Volume 4136, pp. 72-78. [CrossRef]

15. Twiggs, R.J. Space system developments at Stanford University: from launch experience of microsatellites to the proposed future use of picosatellites. In Small Payloads in Space, Proceedings of the International Symposium on Optical Science and Technology, San Diego, CA, USA, 30 July-4 August 2000; Horais, B.J., Twiggs, R.J., Eds.; SPIE: Bellingham, WA, USA, 2000; Volume 4136, pp. 79-86. [CrossRef]

16. Finance, A.; Dufour, C.; Boutéraon, T.; Sarkissian, A.; Mangin, A.; Keckhut, P.; Meftah, M. In-Orbit Attitude Determination of the UVSQ-SAT CubeSat Using TRIAD and MEKF Methods. Sensors 2021, 21, 7361. [CrossRef] [PubMed]

17. BenMoussa, A.; Gissot, S.; Schühle, U.; Del Zanna, G.; Auchère, F.; Mekaoui, S.; Jones, A.R.; Walton, D.; Eyles, C.J.; Thuillier, G.; et al. On-Orbit Degradation of Solar Instruments. Sol. Phys. 2013, 288, 389-434. [CrossRef]

18. Meftah, M.; Dominique, M.; BenMoussa, A.; Dammasch, I.E.; Bolsée, D.; Pereira, N.; Damé, L.; Bekki, S.; Hauchecorne, A. On-orbit degradation of recent space-based solar instruments and understanding of the degradation processes. In Proceedings of the Society of Photo-Optical Instrumentation Engineers (SPIE) Conference Series, Anaheim, CA, USA, 9-13 April 2017; Volume 10196, p. 1019606. [CrossRef]

19. Sperfeld, P.; Metzdorf, J.; Galal Yousef, S.; Stock, K.D.; Möller, W. Improvement and extension of the black-body-based spectral irradiance scale. Metrologia 1998, 35, 267. [CrossRef]

20. Sperfeld, P.; Galal Yousef, S.; Metzdorf, J.; Nawo, B.; Möller, W. The use of self-consistent calibrations to recover absorption bands in the black-body spectrum. Metrologia 2000, 37, 373. [CrossRef]

21. Hersbach, H.; Bell, B.; Berrisford, P.; Hirahara, S.; Horányi, A.; Muñoz-Sabater, J.; Nicolas, J.; Peubey, C.; Radu, R.; Schepers, D.; et al. The ERA5 global reanalysis. Q. J. R. Meteorol. Soc. 2020, 146, 1999-2049. [CrossRef] 